Article

\title{
Novel Mixed Matrix Membranes Based on Polyphenylene Oxide Modified with Graphene Oxide for Enhanced Pervaporation Dehydration of Ethylene Glycol
}

\author{
Mariia Dmitrenko ${ }^{1, * \mathbb{D}}$, Anastasia Chepeleva ${ }^{1}$, Vladislav Liamin ${ }^{1} \mathbb{D}$, Anton Mazur $^{1}$, Konstantin Semenov ${ }^{2}$, \\ Nikolay Solovyev ${ }^{3}$ (D) and Anastasia Penkova ${ }^{1}$ (D)
}

1 St. Petersburg State University, 7/9 Universitetskaya nab., 199034 Saint Petersburg, Russia; chepeleva1999@yandex.ru (A.C.); lyamin.vlad.322@gmail.com (V.L.); a.mazur@spbu.ru (A.M.); a.penkova@spbu.ru (A.P.)

2 Pavlov First Saint Petersburg State Medical University, L'va Tolstogo Ulitsa 6-8, 197022 Saint Petersburg, Russia; semenov1986@yandex.ru

3 Institute of Technology Sligo, Ash Lane, F91 YW50 Sligo, Ireland; solovyev.nikolay@itsligo.ie

* Correspondence: m.dmitrienko@spbu.ru; Tel.: +7-(812)-363-6000 (ext. 3367)

\section{check for}

updates

Citation: Dmitrenko, M.; Chepeleva,

A.; Liamin, V.; Mazur, A.; Semenov,

K.; Solovyev, N.; Penkova, A. Novel Mixed Matrix Membranes Based on Polyphenylene Oxide Modified with Graphene Oxide for Enhanced Pervaporation Dehydration of Ethylene Glycol. Polymers 2022, 14, 691. https://doi.org/10.3390/ polym14040691

Academic Editor: Alessio Fuoco

Received: 11 January 2022

Accepted: 8 February 2022

Published: 11 February 2022

Publisher's Note: MDPI stays neutral with regard to jurisdictional claims in published maps and institutional affiliations.

Copyright: (C) 2022 by the authors. Licensee MDPI, Basel, Switzerland. This article is an open access article distributed under the terms and conditions of the Creative Commons Attribution (CC BY) license (https:// creativecommons.org/licenses/by/ $4.0 /)$.

\begin{abstract}
Ethylene glycol (EG) is widely used in various economic and industrial fields. The demand for its efficient separation and recovery from water is constantly growing. To improve the pervaporation characteristics of a poly(2,6-dimethyl-1,4-phenylene oxide) (PPO) membrane in dehydration of ethylene glycol, the modification with graphene oxide (GO) nanoparticles was used. The effects of the introduction of various GO quantities into the PPO matrix on the structure and physicochemical properties were studied by Fourier-transform infrared (FTIR) and nuclear magnetic resonance (NMR) spectroscopies, scanning electron (SEM) and atomic force (AFM) microscopies, thermogravimetric analysis (TGA), swelling experiments, and contact angle measurements. Two types of membranes based on PPO and PPO/GO composite were developed: dense membranes and supported membranes on a fluoroplast substrate (MFFC). Transport properties of the developed membranes were evaluated in the pervaporation dehydration of EG in a wide concentration range (10-90 wt.\% and 10-30 wt.\% water for the dense and supported membranes, respectively). The supported $\mathrm{PPO} / \mathrm{GO}(0.7 \%) / \mathrm{MFFC}$ membrane demonstrated the best transport properties in pervaporation dehydration of EG (10-30 wt.\% water) at $22{ }^{\circ} \mathrm{C}$ : permeation flux ca. 15 times higher compared to dense PPO membrane-180-230 g/( $\left.\left.\mathrm{m}^{2} \cdot \mathrm{h}\right)\right), 99.8-99.6 \mathrm{wt} . \%$ water in the permeate. The membrane is suitable for the promising industrial application.
\end{abstract}

Keywords: polyphenylene oxide; mixed matrix membrane; graphene oxide; pervaporation; ethylene glycol dehydration

\section{Introduction}

Ethylene glycol (EG) is widely used in the chemical, textile, automotive, and electrical industries [1]. In particular, the applications include the synthesis of polyester fibers, polyethylene glycol, polyethylene terephthalate, polyester, cellophane, polyurethane, and other products, and use in antifreeze, brake fluids, anti-icing fluids, etc. In most involved processes, wastewater with EG is formed. High-purity EG represents a valuable organic matter, so it is justified to extract and regenerate it from the wastewater. It is also worth noting that EG production is usually carried out by hydrolysis of ethylene oxide in the presence of excess water [2]. The enriched result by distillation is a 70-80 wt.\% aqueous solution of ethylene glycol, which requires an additional dehydration step. The further concentration of EG by distillation becomes economically non-feasible, arduous, and energy-intensive, due to the lower water content in the vapor phase and a very high boiling point $\left(197.3^{\circ} \mathrm{C}\right)$ of ethylene glycol [2]. However, the use of pervaporation with the correct 
selection of a membrane with the tailored characteristics makes it possible to easily and energy-efficiently solve the problem of EG recovery from water [3].

Pervaporation, as a membrane process, is related to sustainable possesses; it is an energy-efficient, cost-effective, environmentally friendly, and waste-free method for separating liquid mixtures with low molecular weight substances. A distinctive characteristic of this separation method is the phase transition from liquid to vapor under a driving force, providing high efficiency of separation of azeotropic and isomeric mixtures, close-boiling, and thermally unstable substances [4]. The mechanism of pervaporation consists of three main stages according to the "solubility-diffusion" mechanism and does not depend on the vapor-liquid equilibrium [5]. This method as a diffusive membrane process also allows the sensitive evaluation of the contribution of membrane modification [6]. Nowadays, the majority of research on EG dehydration by pervaporation has focused on the use of polymeric membranes based on a polymer of intrinsic microporosity (PIM-1) [7], polyvinyl alcohol (PVA) [8], polyvinylamine (PVAm)-PVA [9], chitosan [10], polyelectrolyte complexes [11,12], polybenzimidazole/polyetherimide [13], etc. In [7], the PIM-1 membrane was prepared and applied for EG purification from the water/methanol mixtures by pervaporation. It demonstrated a high permeation flux but a moderate separation factor: $50 \mathrm{~g} /\left(\mathrm{m}^{2} \cdot \mathrm{h}\right)$ permeation flux and 39.11 separation factor in pervaporation dehydration of EG (10.33 wt.\% water) at $30{ }^{\circ} \mathrm{C}$, and $211 \mathrm{~g} /\left(\mathrm{m}^{2} \cdot \mathrm{h}\right)$ permeation flux and 12.67 separation factor in pervaporation separation of EG-methanol mixture (11.45 wt. \% methanol) at $30{ }^{\circ} \mathrm{C}$. The transport properties of the PVA membrane for pervaporation dehydration of EG were improved by the modification with zeolite $4 \mathrm{~A}(5 \mathrm{wt} . \%)$ and the development of a supported membrane on a polypropylene microfiltration membrane (substrate) [8]. It was shown that the zeolite $4 \mathrm{~A}$ addition increased the separation factor and improved permeation flux, with $2.65 \mathrm{~kg} /\left(\mathrm{m}^{2} \cdot \mathrm{h}\right)$ and a separation factor of 1972 in pervaporation dehydration of EG (20 wt.\% water) at $70{ }^{\circ} \mathrm{C}$. The supported membranes with a thin selective layer based on a PVAm-PVA blend on a microporous polysulfone (PS) substrate were improved by the modification with carbon nanotubes (CNTs) [9]. The addition of CNTs into the matrix significantly improved the membrane performance only at low feed water concentrations. The PVAm-PVA/CNTs ( $2 \mathrm{wt} . \%)$ membrane had the optimal transport properties: a permeation flux of $146 \mathrm{~g} /\left(\mathrm{m}^{2} \cdot \mathrm{h}\right)$ and a separation factor of 1156 in EG dehydration (1 wt.\% water in the feed) at $70{ }^{\circ} \mathrm{C}$. In [10], the developed supported chitosan/PS membrane had the following parameters: a permeation flux of $0.3 \mathrm{~kg} /\left(\mathrm{m}^{2} \cdot \mathrm{h}\right)$ and a separation factor of 109 ( $92.4 \mathrm{wt} . \%$ water in the permeate) in pervaporation dehydration of EG (10 wt.\% water) at $35^{\circ} \mathrm{C}$. A supported membrane based on polyelectrolyte complex nanoparticles (PEC NPM)graphene oxide (GO) composites on a PS substrate was investigated for pervaporation dehydration of EG [11]. The best membrane PEC NPM/GO (3 wt.\%)/PS had ca. 1.5 times lower permeation flux $\left(961 \mathrm{~g} /\left(\mathrm{m}^{2} \cdot \mathrm{h}\right)\right)$ and ca. 2.5 times higher separation factor (1191) compared to the pristine membrane in dehydrating $10 \mathrm{wt} . \%$ water/EG mixtures at $60{ }^{\circ} \mathrm{C}$. However, these membranes were studied with dehydration only up to $20 \mathrm{wt} . \%$ water in the feed. In [12], polyelectrolyte polyethylenimine/poly(acrylic acid) (PEI/PAA) membranes prepared by layer-by-layer self-assembly (seven double layers) on top of an interfacially polymerized polyamide (PA) substrate were studied for pervaporation dehydration of EG, ethanol, and isopropanol. The pervaporation experiments were carried out only above $20 \mathrm{wt} . \%$ water in the feed. The PEI/PAA/PA membrane demonstrated a permeation flux of ca. $5-15 \mathrm{~g} /\left(\mathrm{m}^{2} \cdot \mathrm{h}\right)$ and a separation factor of ca. $570-410$ in pervaporation dehydration of EG (2-20 wt.\% water) at $22{ }^{\circ} \mathrm{C}$. Polybenzimidazole/polyetherimide (PBI/PEI) dual-layer hollow fiber membranes were studied by the pervaporation dehydration of EG under various conditions [13]. They demonstrated a separation factor of 1763 and a permeation flux of $115 \mathrm{~g} /\left(\mathrm{m}^{2} \cdot \mathrm{h}\right)$ in pervaporation dehydration of EG $(20 \mathrm{wt} . \%$ water $)$ at $60^{\circ} \mathrm{C}$. Although many polymeric membranes were proposed and studied for the pervaporation dehydration of EG, further development of more efficient membranes is still required, maintaining the trade-off of high permeation flux and high selectivity, as well as high stability for purifying EG with high water content in the feed (above $20 \mathrm{wt} . \%$ ). 
Among these membrane polymeric materials, poly(2,6-dimethyl-1,4-phenylene oxide) (PPO) deserves special attention. PPO is an aromatic glassy polymer with high mechanical and thermal stability, resistance to chemical agents, and high permeability to gases [14]. Due to the ease of movement of phenyl rings and large free volume between the polymer chains, this polymer is actively used as a membrane material for diffusion membrane processesgas separation [15-17] and pervaporation [18-22]. However, in spite of its potential, PPO was investigated only in a few studies which addressed the pervaporation regeneration of EG from water [23] and methanol [24,25]. For the separation of EG/water mixtures, the improvement of PPO membranes was achieved by the modification with heteroarm stars (HAS), consisting of a center fullerene $\mathrm{C}_{60}$, six arms of nonpolar polystyrene, and six arms of polar poly-tert-butyl methacrylate [23]. A dense PPO/HAS (5 wt.\%) membrane with the thickness of ca. $40 \mu \mathrm{m}$ was tested in the pervaporation dehydration of EG (5-12 wt.\% water) at $50{ }^{\circ} \mathrm{C}$ and demonstrated the optimal transport properties: ca. $0.003-0.013 \mathrm{~kg} /\left(\mathrm{m}^{2} \cdot \mathrm{h}\right)$ permeation flux and 32,500-10,000 separation factor (ca. $99.9 \mathrm{wt}$ \% water in the permeate). However, for the promising application of PPO membranes in industrial processes of EG dehydration, highly efficient supported membranes with a thin selective layer on porous substrates are required. Thus, the selection of another modifier and the creation of supported PPO membranes are a promising direction to improve the transport properties enhancing EG dehydration.

In the present work, the improvement of PPO membrane performance for dehydration of EG was achieved by the modification with one of the most promising carbon nanoparticles-graphene oxide (GO). GO is obtained by oxidation of graphite, and it is possible to obtain various GO structures depending on the applied method [26]. Graphene oxide has unique structural properties, good dispersion in polymer matrices, and functional oxygen-containing groups. However, at present, GO still has limited use as a nanotailored material, due to a low adsorption capacity and weak interfacial interaction [27]. One of the most promising ways is to use GO as a modifier of polymeric membranes to enhance their properties and sustainability in gas separation and water purification [28-31]. However, to the best of our knowledge, there are no works on the use of mixed matrix PPO membranes with GO modification in pervaporation [32]. The introduction of a carbon nanomodifier such as GO into a PPO membrane would significantly affect the hydrophilic-hydrophobic balance of the surface, change the crystallinity and morphology of the polymer matrix, and change the free volume between polymer chains, causing significantly enhanced transport properties in pervaporation [6].

Thus, the aim of the study was to improve the pervaporation characteristics of a membrane based on poly(2,6-dimethyl-1,4-phenylene oxide) in the dehydration of ethylene glycol by the modification with graphene oxide nanoparticles and the developing of highperformance supported membranes for promising industrial applications. The effect of the introduction of the various GO quantities into the polymer matrix on the structural, physicochemical, and transport properties of the PPO-based membranes was investigated. Two types of membranes were developed: dense and supported on a fluoroplast substrate (MFFC). The supported membranes with a thin selective layer deposited onto a porous MFFC substrate were created to significantly increase the membrane permeability and for the potential implementation in industry. The structure and physicochemical properties of the developed membranes were studied by spectroscopic (FTIR and NMR) and microscopic (SEM and AFM) techniques, thermogravimetric analysis (TGA), swelling experiments, and contact angle measurements. Transport properties of the PPO-based membranes were tested in the pervaporation dehydration of EG in a wide concentration range (10-90 wt.\% and 10-30 wt.\% water in the feed for the dense and supported membranes, respectively).

\section{Materials and Methods}

\subsection{Materials}

Poly(2,6-dimethyl-1,4-phenylene oxide) (PPO, $1.06 \mathrm{~g} / \mathrm{mL}$ at $25^{\circ} \mathrm{C}$, Sigma-Aldrich, St. Petersburg, Russia) was used as a membrane matrix. Graphene oxide (GO, Fullerene 
Technologies, St. Petersburg, Russia) synthesized from graphite by an oxidation reaction using a modified Hummers and Offeman method [33] was used as a modifier of the PPO membranes. Commercial porous hydrophobic membrane MFFC (Vladipor, Vladimir, Russia) based on fluoroplast F42L was used as a support for the preparation of the supported PPO-based membranes. Chloroform $\left(\mathrm{CHCl}_{3}\right.$, purity $\geq 99.1 \mathrm{wt}$ \%), ethylene glycol (EG, purity $\geq 99.9$ wt.\%), and methanol (MeOH, purity $\geq 99.5$ wt.\%) were purchased from Vekton (St. Petersburg, Russia) and used without additional treatment.

\subsection{Membrane Preparation}

The preparation of PPO/GO composites was carried out by solid-phase synthesis [34]. The pre-determined amount of polymer powder was ground with the calculated quantity of GO $(0.1,0.3,0.5,0.7,0.9 \mathrm{wt}$.\% with respect to the polymer weight). The obtained composite was dissolved in chloroform under constant stirring for $3 \mathrm{~h}$ at ambient temperature to obtain $8 \mathrm{wt}$ \% PPO solution with the consequent ultrasonic treatment for $30 \mathrm{~min}$ at ambient temperature for degassing the polymer solution [35]. Dense PPO and PPO/GO membranes were formed by solvent evaporation technique: pouring pre-determined PPO solution or composite onto the cellophane surface fixed on a hollow steel ring, drying in an oven at $40{ }^{\circ} \mathrm{C}$ for $12 \mathrm{~h}$ to remove the solvent, and then separating the membrane from the cellophane following [36]. The thickness of the dense PPO-based membranes measured by a micrometer was equal to $35 \pm 5 \mu \mathrm{m}$.

Supported membranes were prepared by the deposition of the prepared polymer solution and composite onto commercial porous MFFC membrane to form a thin selective layer based on the PPO and PPO/GO (0.7\%) composite in the following manner. The MFFC substrate was fixed on a hollow steel ring, the PPO solution or composite were cast onto the substrate from the side of the ring, and the excess casting solution was removed. Then, the membranes were left to dry at ambient temperature for $24 \mathrm{~h}$ to evaporate the solvent. The preparation scheme of the dense and supported membranes is summarized in Figure 1.

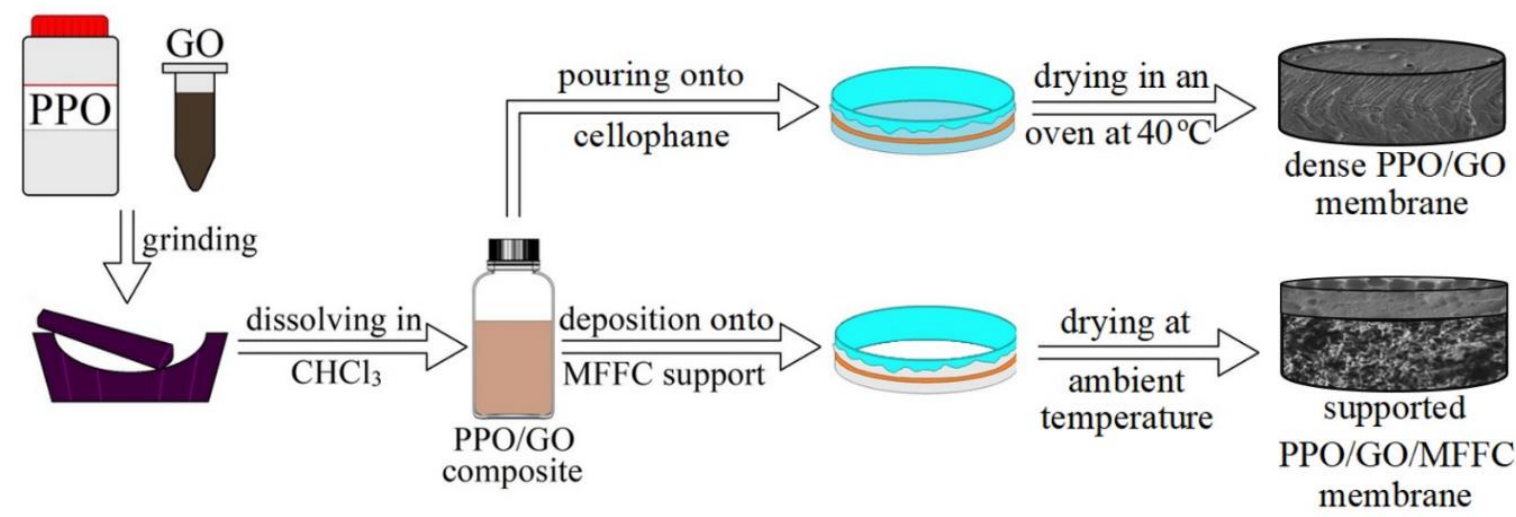

Figure 1. The preparation scheme of the PPO-based membranes.

\subsection{Pervaporation}

The PPO-based membranes were evaluated in pervaporation separation of ethylene glycol/water mixture (10-90 wt.\% water) in a steady-state cell at $22{ }^{\circ} \mathrm{C}$ with a membrane area of $9.61 \mathrm{~cm}^{2}$ and $<10^{-1} \mathrm{~mm} \mathrm{Hg}$ downstream pressure $[37,38]$. The scheme of pervaporation setup is demonstrated in Figure 2. 


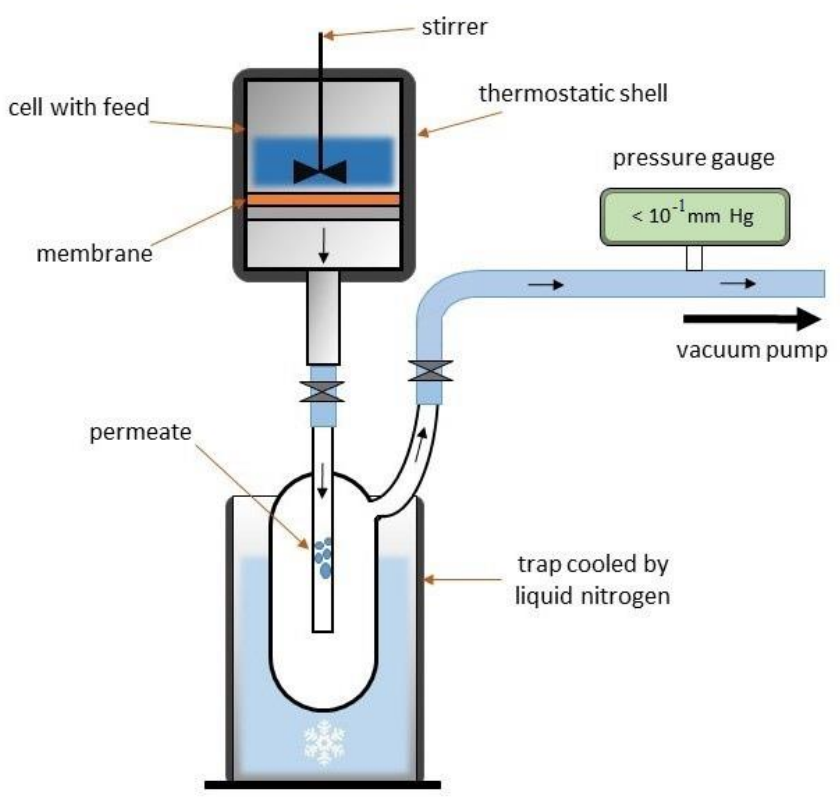

Figure 2. The scheme of the pervaporation setup.

The transport properties of the PPO-based membranes are presented in terms of permeation flux, component permeances, water content in the permeate, and separation factor.

Permeation flux $(J)$ of the membranes was calculated according to the following equation [39]:

$$
J=\frac{W}{A \cdot t}
$$

where $W$ is the weight of permeate collected in a trap cooled by liquid nitrogen $(\mathrm{kg}), A$ is the membrane area $\left(\mathrm{m}^{2}\right)$, and $t$ is the time of permeate collection (h).

The separation factor $(\beta)$ was calculated according to the following equation [40]:

$$
\beta=\frac{\frac{y_{i}}{y_{j}}}{\frac{x_{i}}{x_{j}}}
$$

where $y_{i}$ and $y_{j}$ are the $i$ and $j$ component contents in the permeate, and $x_{i}$ and $x_{j}$ are the $i$ and $j$ component contents in the feed.

The component permeances $(P / l)$ (a component flux normalized for driving force) were calculated according to the following equation [40]:

$$
\frac{P}{l}=\frac{j_{i}}{p_{i_{f}}-p_{i_{p}}},
$$

where $j_{i}$ is the partial component flux, $l$ is the membrane thickness, and $p_{i_{f}}$ and $p_{i_{p}}$ are vapor pressures of components in the feed and the permeate, respectively. The permeance was calculated in common gas permeation units (GPU) according to Baker et al. [40].

The permeate was analyzed by gas chromatography with a Chromatek Crystal 5000.2 chromatograph (Chromatec, Nizhny Novgorod, Russia) equipped with a Hayesep R column (Chromatec, Nizhny Novgorod, Russia). Pervaporation experiments were carried out at least three times for each membrane type; then, average values of the parameters were calculated and taken for analysis. The transport parameters' mean accuracy of the PPO-based membranes was $\pm 0.5 \%$ for water content in the permeate, and $\pm 10 \%$ and $\pm 15 \%$ for the permeation flux of the dense and supported membranes, respectively. 


\subsection{Fourier-Transform Infrared Spectroscopy (FTIR)}

The structural changes during the modification of PPO with GO were studied by FTIR spectroscopy using an IRAffinity-1S spectrometer (Shimadzu, St. Petersburg, Russia) and an attenuated total reflectance (ATR) accessory (PIKE Technologies, St. Petersburg, Russia) in the range of $500-4000 \mathrm{~cm}^{-1}$ at $25^{\circ} \mathrm{C}$.

\subsection{Nuclear Magnetic Resonance (NMR)}

NMR study of PPO-based membranes was carried out using a Bruker Avance III 400 WB NMR spectrometer (Bruker, Bremen, Germany) with a CP/MAS probe of $4 \mathrm{~mm}$ and a magnetic field of 9.4 T. Larmor frequency for nuclei ${ }^{13} \mathrm{C}$ was $100.64 \mathrm{MHz}$. Liquid tetramethylsilane (TMS) was applied as an external reference for ${ }^{13} \mathrm{C}$ nuclei.

\subsection{Scanning Electron Microscopy (SEM)}

The morphology of the inner and surface structure of PPO-based membranes was investigated by SEM using a Zeiss Merlin SEM (Carl Zeiss SMT, Oberhochen, Germany) at a low accelerating voltage $(1 \mathrm{kV})$ and the low electron beam current $(100 \mathrm{pA})$ preventing surface modification and charging.

\subsection{Atomic Force Microscopy (AFM)}

The surface of the developed PPO-based membranes was studied by AFM with an NTMDT NTegra Maximus atomic force microscope (NT-MDT Spectrum Instruments, Moscow, Russia) with standard silicon cantilevers $\left(15 \mathrm{~N} \cdot \mathrm{m}^{-1}\right.$ rigidity) in the tapping mode.

\subsection{Thermogravimetric Analysis (TGA)}

The thermochemical stability of the PPO-based membranes was investigated by TGA using a Thermobalance TG 209 F1 Libra (Netzsch, Leuna, Germany) under argon atmosphere and in a temperature range of $30-950{ }^{\circ} \mathrm{C}$ with a $10 \mathrm{~K} / \mathrm{min}$ heating speed.

\subsection{Contact Angle Measurements}

Contact angles of water were measured by the sessile drop method with a Goniometer LK-1 instrument (Ltd. NPK Open Science, Krasnogorsk, Russia) to assess the hydrophilichydrophobic properties of the surface of the PPO-based membranes. To analyze contact angle results, the DropShape software (Ltd. NPK Open Science, Krasnogorsk, Russia) was used.

\subsection{Swelling Experiments}

The swelling degree of the dense PPO-based membranes in water and EG was measured by a gravimetric method at $22{ }^{\circ} \mathrm{C}$. The weighed membranes were immersed in the corresponding liquids and weighed daily until the constant swelling weight. The swelling degree $(S)$ of the PPO-based membranes was calculated as follows:

$$
S=\frac{m_{s}-m_{0}}{m_{0}},
$$

where $m_{0}$ is the initial membrane weight $(\mathrm{g})$, and $m_{S}$ is the swollen membrane weight $(\mathrm{g})$.

\section{Results}

This section is divided into four main parts. Section 3.1 is devoted to the investigation of transport properties of the dense and supported PPO and PPO/GO membranes in the pervaporation dehydration of EG. Section 3.2 is dedicated to the study of structural and physicochemical properties of the developed PPO-based membranes to explain and describe the obtained transport characteristics and mass transfer of the components through the membranes. In Section 3.3, the comparison of pervaporation performance of membranes based on the $\mathrm{PPO} / \mathrm{GO}(0.7 \%)$ composite with literature-described polymeric membranes is presented. 


\subsection{Transport Properties of the PPO-Based Membranes}

To study the effect of modification with graphene oxide, PPO membranes with different modifier quantities $(0.1,0.3,0.5,0.7$, and $0.9 \mathrm{wt} . \%)$ were tested in the pervaporation dehydration of EG in a wide concentration range (10-90 wt.\% water), also assessing the effects of feed composition. Figure 3 displays transport characteristics of the developed membranes in terms of permeation flux, water content in the permeate, and component permeances.

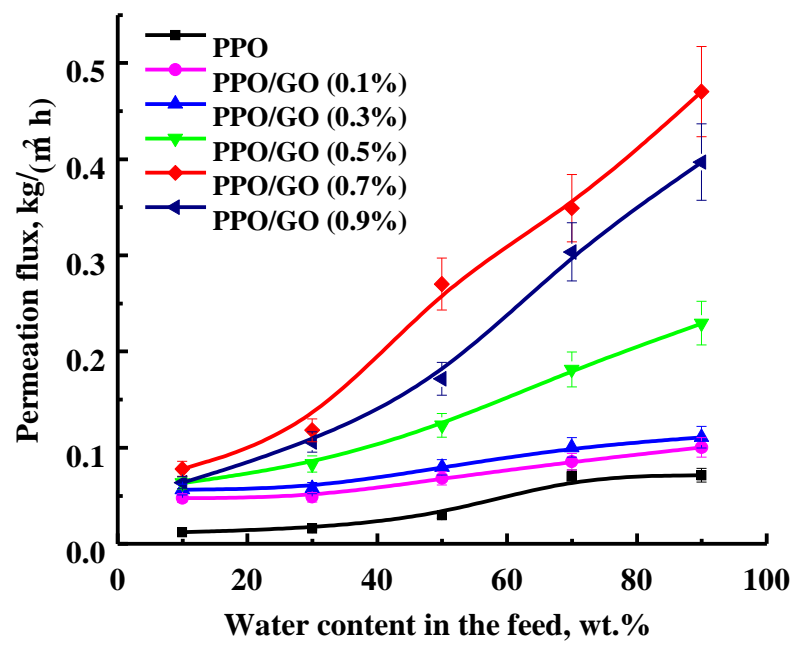

(a)

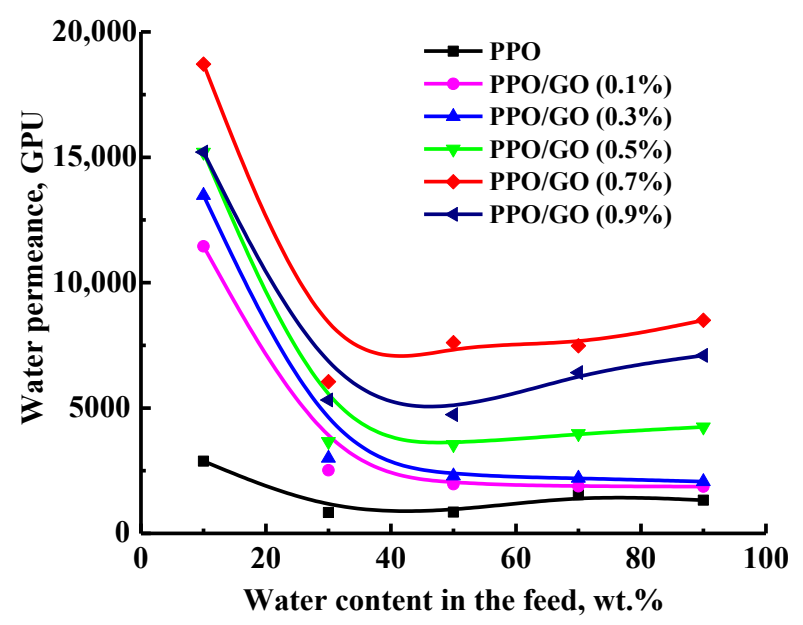

(c)

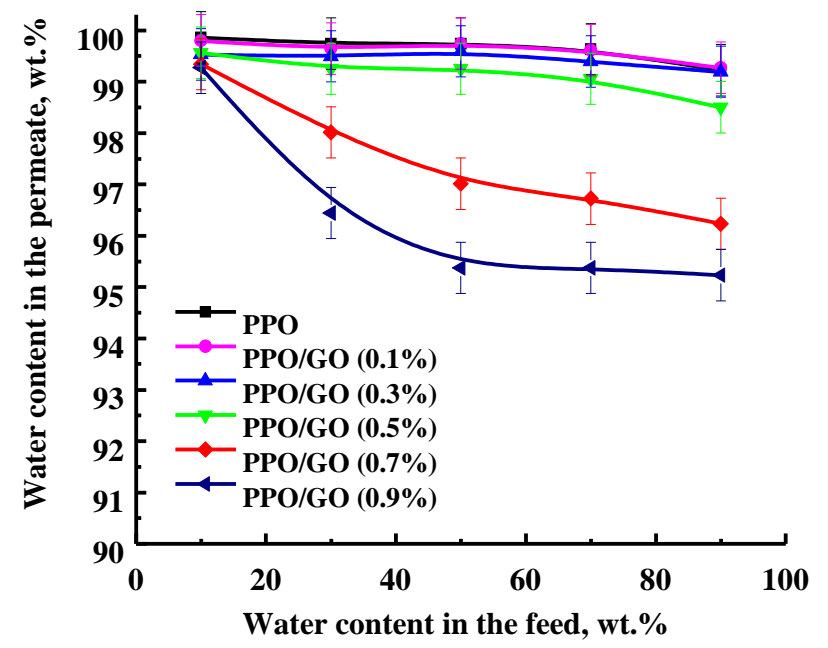

(b)

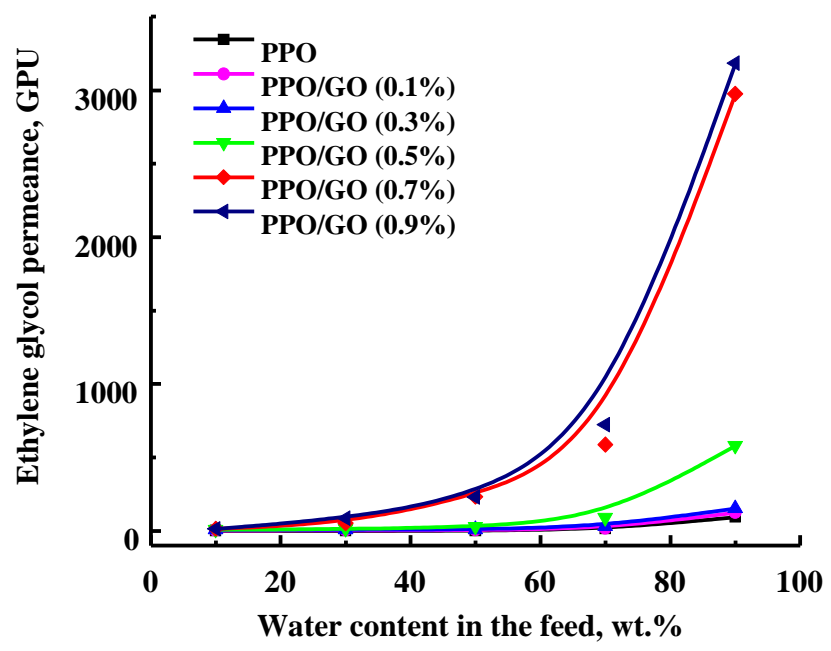

(d)

Figure 3. The dependence of (a) permeation flux, (b) water content in the permeate, and (c,d) component permeances on the water content in the feed in pervaporation separation of ethylene glycol/water mixture (10-90 wt.\% water) for the dense PPO and PPO/GO membranes.

Although PPO polymer has phenyl groups and is hydrophobic, PPO-based membranes are known to transmit small molecules (for example, water) in vacuum pervaporation [41]. As pervaporation is described by a solubility-diffusion mechanism [42], one of the most robust approaches to evaluate the interaction between PPO and components of the feed (water and EG) is the use of Hansen's solubility parameters. According to the theory of solubility, a smaller difference in the solubility parameters of the polymer and the liquid contributes to stronger interaction of this liquid with the polymer, causing a higher sorption 
degree of the component in the polymer [37]. The data on solubility parameters of water $\left(49.6\left(\mathrm{~J} / \mathrm{cm}^{3}\right)^{1 / 2}\right)$, EG $\left(32.9\left(\mathrm{~J} / \mathrm{cm}^{3}\right)^{1 / 2}\right)$, and PPO $\left(18.2\left(\mathrm{~J} / \mathrm{cm}^{3}\right)^{1 / 2}\right)$ are presented in [23]. A smaller difference between solubility parameters of the EG and PPO $\left(\Delta=14.7\left(\mathrm{~J} / \mathrm{cm}^{3}\right)^{1 / 2}\right)$ is shown, which suggests a higher EG solubility and sorption in PPO membranes than in water. The increased membrane swelling (sorption) in EG was also confirmed by swelling data in Section 3.2.1. The mechanism of mass transfer of the EG/water mixture through the PPO-based membranes may be described as follows: EG initially interacts with PPO through hydrogen bonds due to its higher solubility in the membrane and creates transport channels; then, water penetrates into the channels, the size of which is commensurate with the kinetic diameter of a water molecule [41]. All developed PPO-based membranes were confirmed to be highly selective to water (Figure $3 b$ ). The obtained data demonstrate that the permeation flux and water content in the permeate of both pristine PPO and modified $\mathrm{PPO} / \mathrm{GO}$ membranes are a function of the water content in the feed: with the rise in water in the feed, the water content in the permeate slightly decreases, and the permeation flux of all membranes increases [43].

The introduction of GO into the PPO matrix improved the permeation flux with a slight decrease in selectivity with respect to water, compared to the unmodified PPO membrane (Figure $3 \mathrm{a}, \mathrm{b}$ ). It is also worth noting that the observed changes propagated with an increase in the GO concentration up to $0.7 \mathrm{wt} . \%$ in the membrane, except for the membrane with 0.9 wt. $\%$ GO. The PPO/GO (0.9\%) membrane had lower permeation flux and water content in the permeate compared to the PPO/GO $(0.7 \%)$ membrane. It may be related to the agglomeration of GO particles in the PPO matrix, causing the hindered mass transfer of the components through the membrane, which decreased the membrane's permeability. Moreover, the agglomeration of GO particles led to the formation of defects in the membrane due to selective exfoliation on the interface between the polymer matrix and agglomerated nanoparticles phase [24], which initiated additional transport channels for both water and EG, reducing the selectivity of the membrane [44]. The improvement in permeability of the GO-modified membranes is associated with a change in the inner and surface structure: an increase in the roughness and amorphous phase of the matrix morphology and in the surface roughness and its hydrophilization during the modification process (confirmed by NMR, SEM, AFM, and contact angle data-see below). However, with an increase in water content in the feed, the membranes swelled more, leading to plasticization of the membrane and increasing the free volume between polymer chains, resulting in simultaneous penetration of EG and water and a decrease in the selective properties (Figure 3b). The optimal transport characteristics were exhibited by the PPO/GO $(0.7 \%)$ membrane: the highest permeation flux ( $\geq 5$ times higher compared to the pristine PPO membrane) with a slight decrease in selective properties (99.3-96.2 wt.\% water in the permeate), while water content in the permeate for PPO membrane reached 99.9-99.2 wt.\%.

The transport properties of the PPO-based membranes were considered in terms of component permeances (a component flux normalized for the driving force), related to the intrinsic properties of the membranes (Figure 3c,d). After normalizing for the driving force, it was observed that the dependence of permeation flux from water concentration in the feed (Figure 3a) was mostly related to the changes in water and EG vapor pressure (driving force) with the concentration [40]. An increase in the feed water content means a decrease in the EG concentration, resulting in the enhanced driving force for the water penetration through the membrane and depressed driving force for the EG penetration. Water permeance for all membranes was significantly higher than the EG permeance, due to the special mass transfer mechanism manifesting for the PPO-based membranes [3]. Thus, the permeation flux was dominated by the flux of water. However, in contrast to permeation flux (Figure 3a), water permeance for the modified membranes was found to decrease. The water permeance was high at a low concentration $(10 \mathrm{wt} . \%$ water in the feed) but decreased to a plateau value at the concentration above $30 \mathrm{wt} . \%$ water in the feed (Figure 3c). It may be related to a significant increase in fugacity of water with feed concentration compared to EG [45]. A similar trend for the permeation flux and component 
permeabilities (alternative to permeances) was considered for the separation of acetic acidwater mixtures using mixed matrix copolymer membranes in [45]. The PPO/GO $(0.7 \%)$ membrane had the highest values of water permeance, which is in agreement with the highest permeation flux (Figure 3a). However, this membrane was also characterized by high values of EG permeance, which may be associated with the swelling of the membrane due to the modification (confirmed below by swelling data) and its plasticization in the feed.

For the promising industrial application in EG regeneration of the PPO/GO $(0.7 \%)$ membrane with optimal transport properties, the development of a supported membrane was carried out by the deposition of a thin selective layer based on PPO and $\mathrm{PPO} / \mathrm{GO}(0.7 \%)$ composite onto a porous MFFC substrate. All commercial industrial membranes are supported due to better mechanical strength and enhanced permeability. It was found that energy consumption for EG dehydration using membrane technologypervaporation - can be significantly reduced if the concentration of EG in the mixture exceeds $70 \mathrm{wt} . \%[1,2,46]$. Thus, transport properties of the obtained supported PPO/MFFC and PPO/GO $(0.7 \%) / M F F C$ membranes were tested in pervaporation dehydration of EG (10-30 wt.\% water) and compared with the dense membranes (Figure 4).

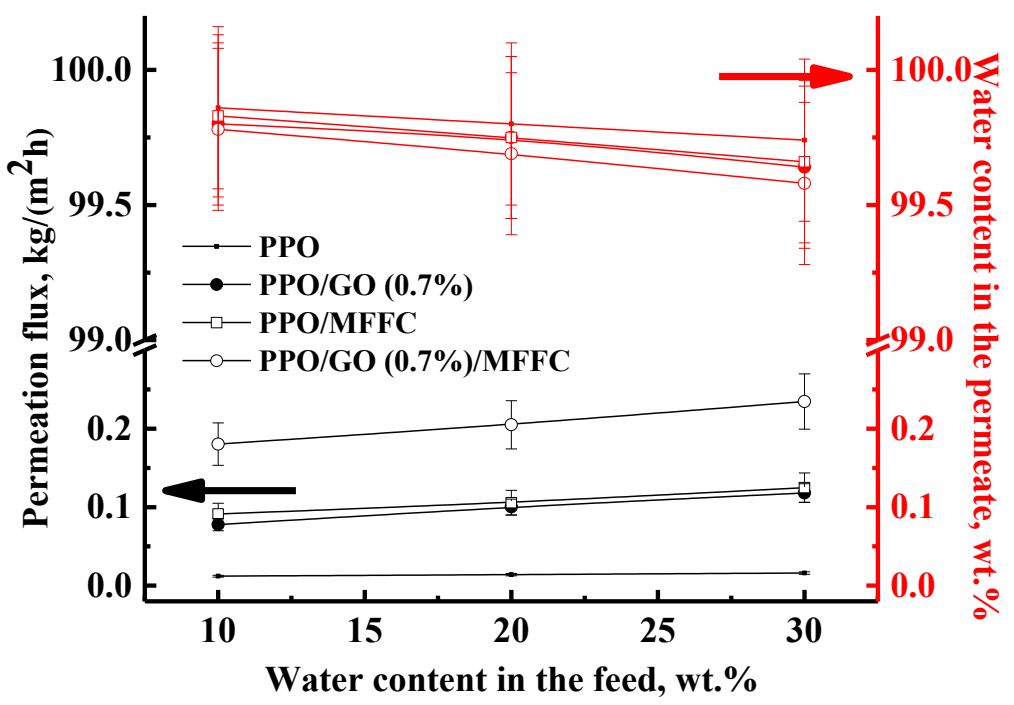

Figure 4. The dependence of permeation flux and water content in the permeate on the water content in the feed in pervaporation separation of ethylene glycol/water mixture (10-30 wt. \% water) for the dense and supported membranes based on the PPO and PPO/GO (0.7\%) composite.

The development of the supported membranes led to the increased permeation flux by ca. 8 and 2 times for the membranes based on the PPO and PPO/GO (0.7\%) composite, respectively. Moreover, high selectivity with respect to water (99.8-99.7 wt. $\%$ and 99.8-99.6 wt.\% water in the permeate, respectively) was maintained. The reason for the permeation flux enhancement was related to a significant decrease in the thickness of the dense selective layer of the membrane (confirmed by SEM below). A smaller degree of increase in permeation flux for the modified membrane may be associated with the presence of GO nanoparticles in the thin selective layer, which can hinder the mass transfer of the components through the membrane [34]. The developed supported PPO/GO $(0.7 \%) /$ MFFC membrane (modified with $0.7 \mathrm{wt} . \% \mathrm{GO}$ ) had the best transport properties (the highest permeation flux, which is ca. 15 times higher compared to the dense pristine PPO membrane, maintaining high selectivity) for the pervaporation dehydration of EG (10-30 wt.\% water), and is promising for the industrial application for EG regeneration. 


\subsection{The Characterization of PPO-Based Membranes}

\subsubsection{The Study of the Dense Membranes}

To study the effect of modification with GO, the structural characteristics of the developed PPO-based membranes were investigated by FTIR and NMR spectroscopies, SEM, and AFM methods. FTIR spectra of the PPO and PPO/GO (0.7\%) membranes, with optimal transport properties, are presented in Figure 5.

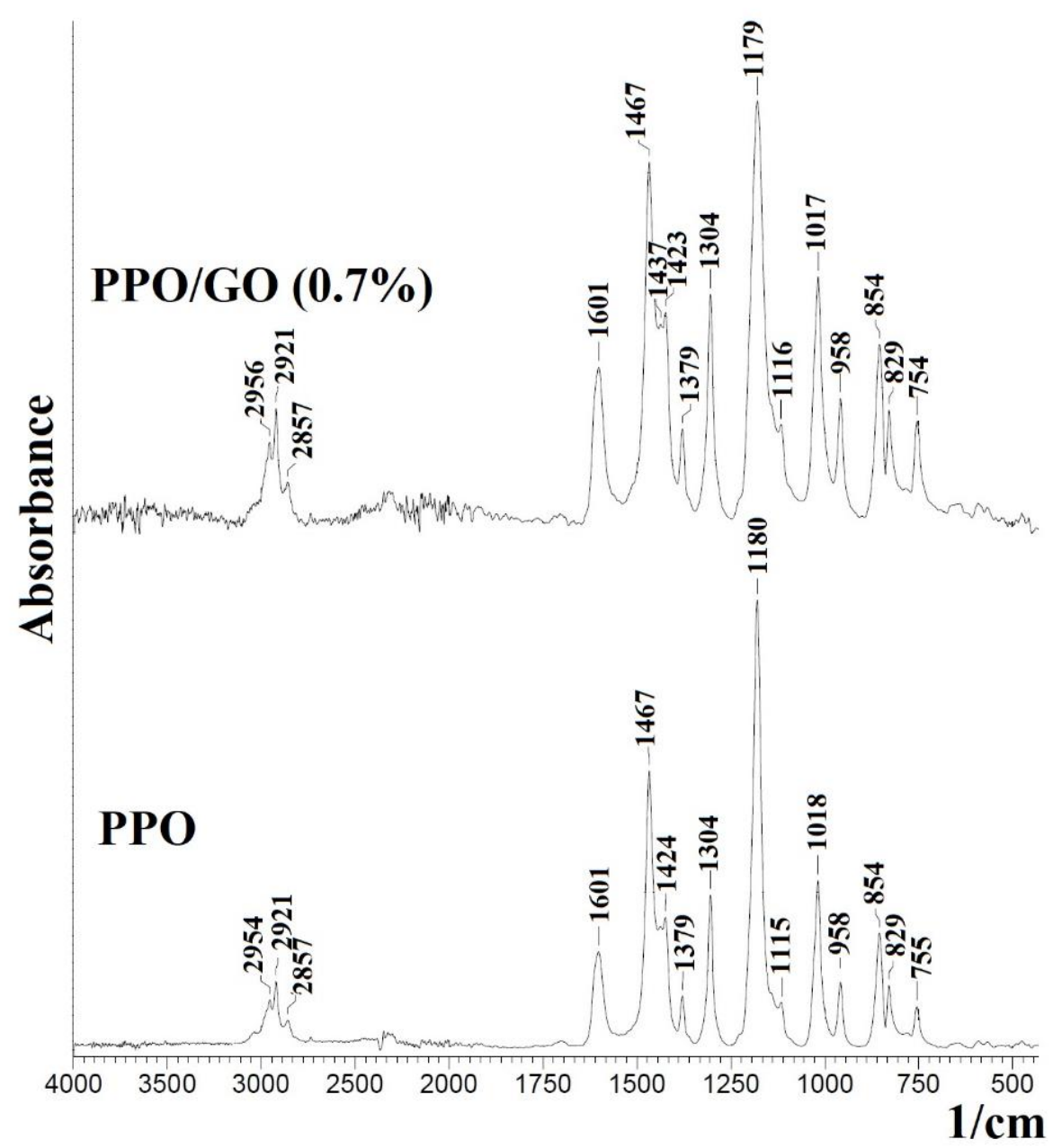

Figure 5. FTIR spectra of the PPO and PPO/GO (0.7\%) membranes.

The FTIR spectrum of pristine PPO membrane demonstrates the characteristic absorption bands. The peak at $2954 \mathrm{~cm}^{-1}$ corresponds to vibrations of aromatic $\mathrm{C}-\mathrm{H}$ bonds. The peaks at 2921 and $2857 \mathrm{~cm}^{-1}$ belong to asymmetric and symmetric vibrations of $-\mathrm{CH}_{2}$ groups. The peaks at 1601 and $1467 \mathrm{~cm}^{-1}$ correspond to the vibrations of $\mathrm{C}=\mathrm{C}$ and $\mathrm{C}-\mathrm{H}$ of the benzene ring, respectively, and the peaks at 1180 and $1304 \mathrm{~cm}^{-1}$ refer to symmetric and asymmetric vibrations of the $\mathrm{C}-\mathrm{O}$ bond [47]. It should be noted that the introduction of $0.7 \mathrm{wt} . \%$ GO into the PPO matrix did not significantly change the band position and intensity. In the spectrum of the modified PPO/GO $(0.7 \%)$ membrane, characteristic peaks of GO are not observed: the wide peak around $3440 \mathrm{~cm}^{-1}$ related to the $-\mathrm{OH}$ stretching of the carboxylic group, the peak at $1718 \mathrm{~cm}^{-1}$ attributed to the $\mathrm{C}=\mathrm{O}$ stretching of the carboxylic groups, the peak at $1630 \mathrm{~cm}^{-1}$ corresponded to the $\mathrm{C}=\mathrm{C}$ stretch of the aromatic domain of graphene, etc. $[48,49]$. These bands may be invisible due to the low $\mathrm{GO}$ content in the membrane matrix and indicate weak interactions between the polymer and the particles of the modifier. 
The structural changes in the GO-modified PPO membranes were confirmed by NMR spectroscopy. Figure 6 demonstrates a schematic representation of a PPO monomer with numbered nonequivalent carbon atoms and the ${ }^{13} \mathrm{C}$ NMR spectrum of the pristine PPO membrane.

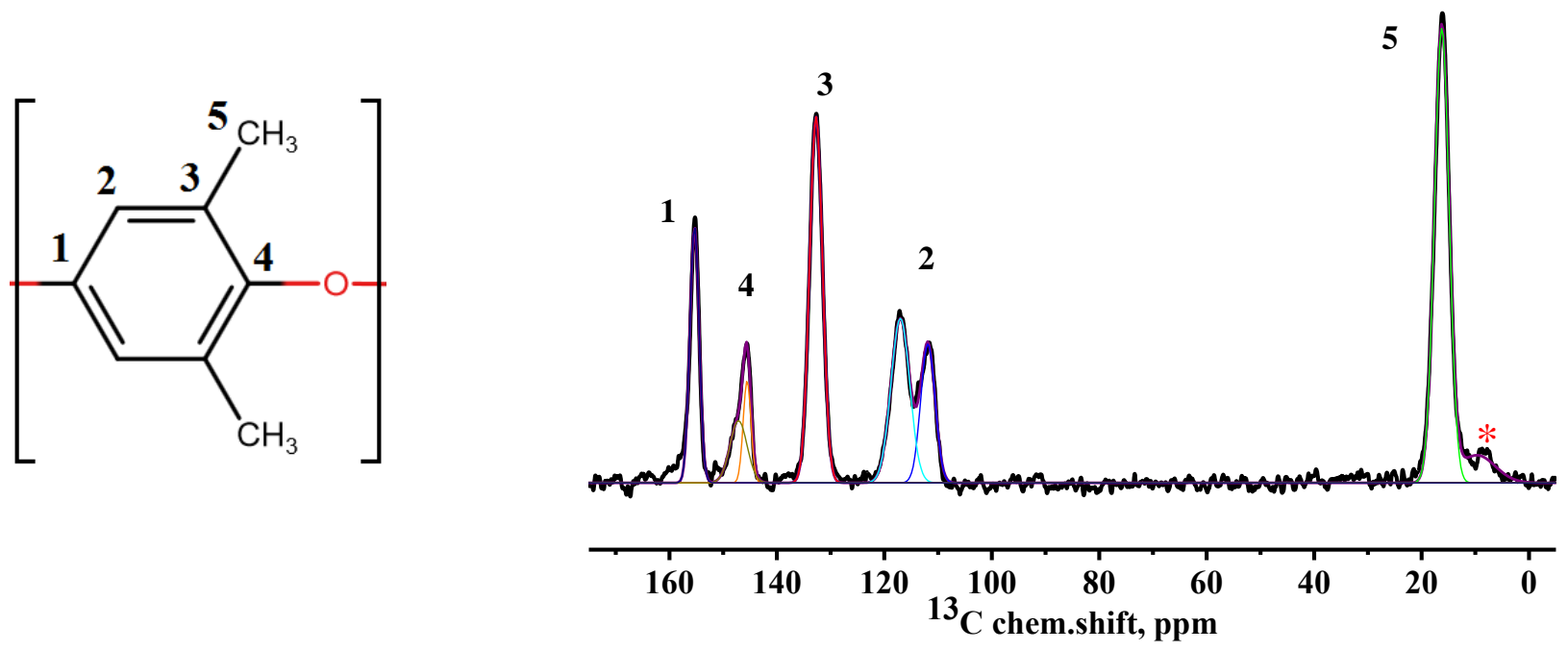

(a)

(b)

Figure 6. (a) Schematic representation of a PPO monomer with numbered nonequivalent carbon atoms and (b) ${ }^{13} \mathrm{C}$ NMR spectrum of the pristine PPO membrane.

The spectrum shows the presence of five allowed spectral components, each of which corresponds to carbon atoms in different nonequivalent positions (Figure 6a). There is a weak peak (asterisk in Figure 6b) near the line, corresponding to the methyl groups of PPO. This peak is a rotation satellite (SSB) from the line at position 3 of the polymer unit. In addition, it can be seen that the spectral line, related to the carbon atoms in position 4, is divided into two weakly resolved components. This may be related to the presence of regions with regular conformational packing of polymer units in the polymer structure [50]. Since the component (at $112 \mathrm{ppm}$ ) has a smaller width, it can be assumed to correspond to the conformationally ordered phase of the polymer. The change in the content of the conformationally ordered phase in the samples during the modification with GO is possible to estimate by evaluating the ratio of the integral areas of the two components in the spectrum (Figure 7). In turn, the spectral line, corresponding to the atoms in the position 4 , has an inhomogeneously broadened shape. This may indicate the presence of two unresolved components. The presence of two components at carbon atoms, which are connected with the interlink oxygen atom, can be associated with the presence of an NMR crystalline phase in the volume of the studied membranes. As in the previous case, the line at about $145.5 \mathrm{ppm}$ is characterized by a smaller width, which indicates that it belongs to the atoms of the ordered phase. The content of the NMR crystalline phase in the developed membranes was also evaluated by the estimation of the ratio of the integral areas of these two lines (Figure 7).

The obtained data demonstrate that the PPO/GO (0.1\%) membrane with a minimum content of the modifier has a slight increase in the proportion of regular conformation structure compared to the pristine PPO membrane. With a further increase in the GO concentration in the membranes, the amount of the conformationally ordered phase, at first, decreases monotonically and reaches a minimum at a GO quantity of $0.5 \mathrm{wt} . \%$, and then a slight increase is observed. This effect indicates that the modification changes the conformation of the polymer chains with a more uneven distribution in the volume. This forms a larger free volume between the PPO chains, reflecting the improved permeability of the modified membranes. For the NMR crystalline phase, another trend of changes is observed: for the PPO membranes with 0.1-0.5 wt.\% GO, an insignificant decrease in the 
amount of the crystalline phase is detected. At the same time, the rise in GO content from 0.7 to $0.9 \mathrm{wt} . \%$ in the PPO matrix led to a sharp drop in the content of the NMR crystalline phase. This indicates that the introduction of GO into the PPO matrix forms a membrane with a more amorphous structure, resulting in an increased permeation flux for the modified membranes during EG dehydration (Figure 3a). The NMR data are in agreement with transport membrane characteristics (see above) and the SEM data, described below.

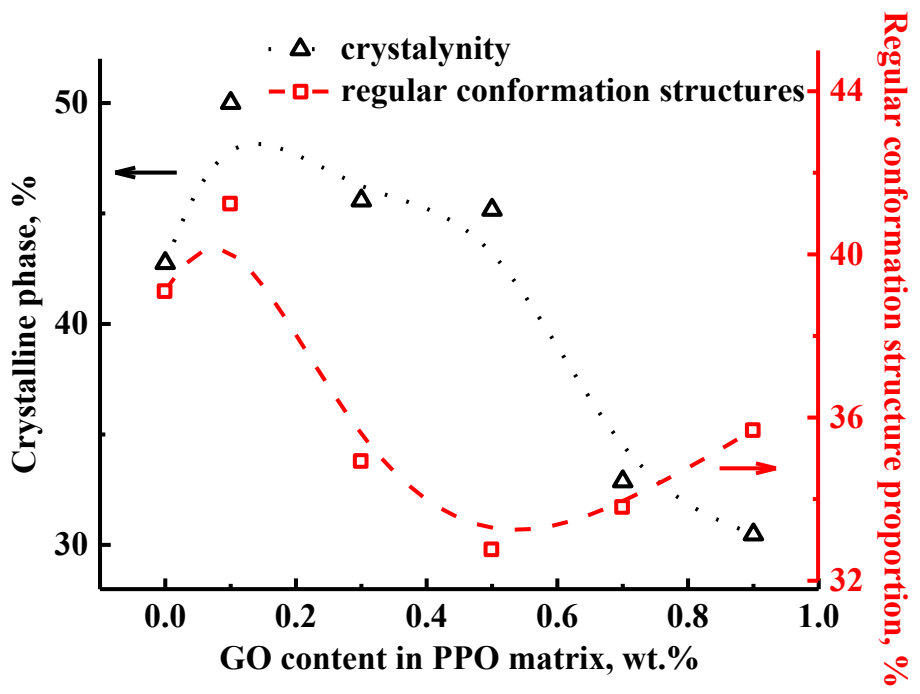

Figure 7. The dependences of crystalline phase and regular conformation structure proportion on the GO content in the PPO matrix.

The morphology of the dense PPO-based membranes was studied by SEM; significant changes were observed even at low GO concentrations in the membrane matrix (Figure 8).

The presented micrographs demonstrate a uniform surface structure with rounded cavities and a cross-sectional structure with uniform plastic deformations of the unfilled PPO membrane (Figure 8a). The introduction of GO into the polymer matrix changed these deformations, which became significant and stronger with the increase in the modifier content. The modification with the lowest GO content $(0.1 \mathrm{wt} . \%)$ slightly altered the crosssection, but formed a surface with a rougher structure (a ridge-and-valley structure) [51] and increased the number of rounded cavities. The formation of more cavities with a larger size may be related to the aggregation of the modifier particles and the phase separation of the PPO and the GO [44]. With the increase in GO concentration (from 0.3 to 0.9 wt.\%), the plastic deformations of the cross-section and the surface roughness with rounded cavities increased significantly. The maximum roughest cross-sectional structure and number of cavities and the GO particles on the surface were observed for the PPO/GO (0.9\%) membrane, which was consistent with the maximum surface roughness values (confirmed below by AFM data). It is worth clarifying that the GO particles were not visible in the cross-sectional structure of all modified membranes, which could indicate their uniform dispersion in the polymer matrix [51,52].

The surface topography of the developed PPO-based membranes was additionally studied by AFM to confirm the surface SEM data (Figure 9). 
(a)

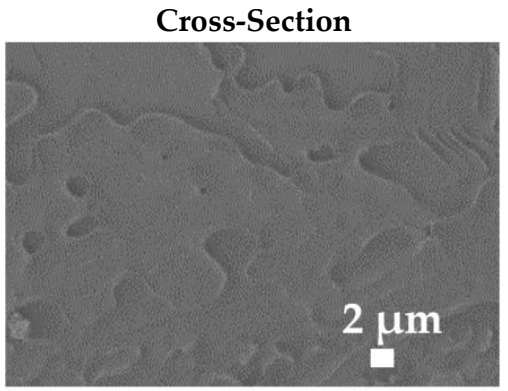

Surface

(b)

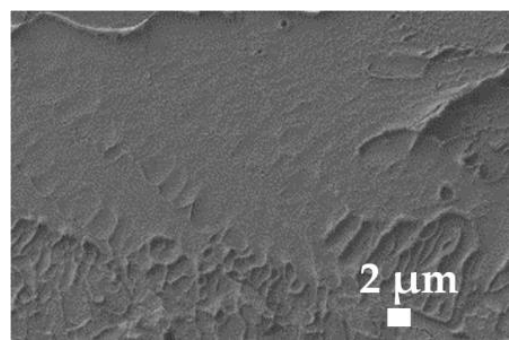

(c)

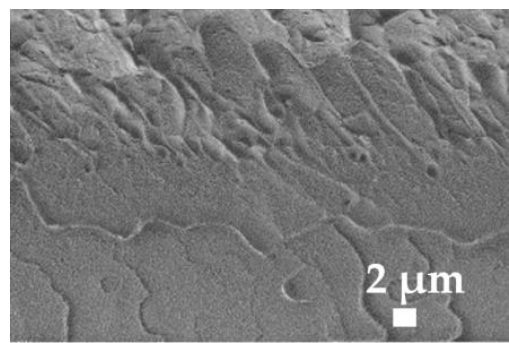

(d)

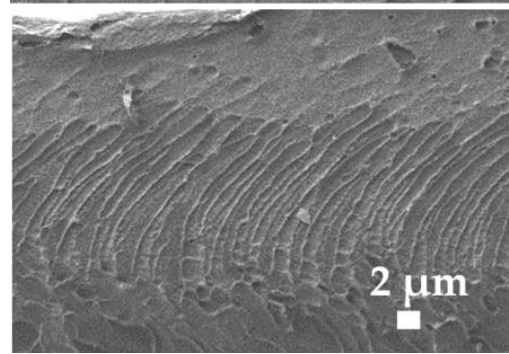

(e)
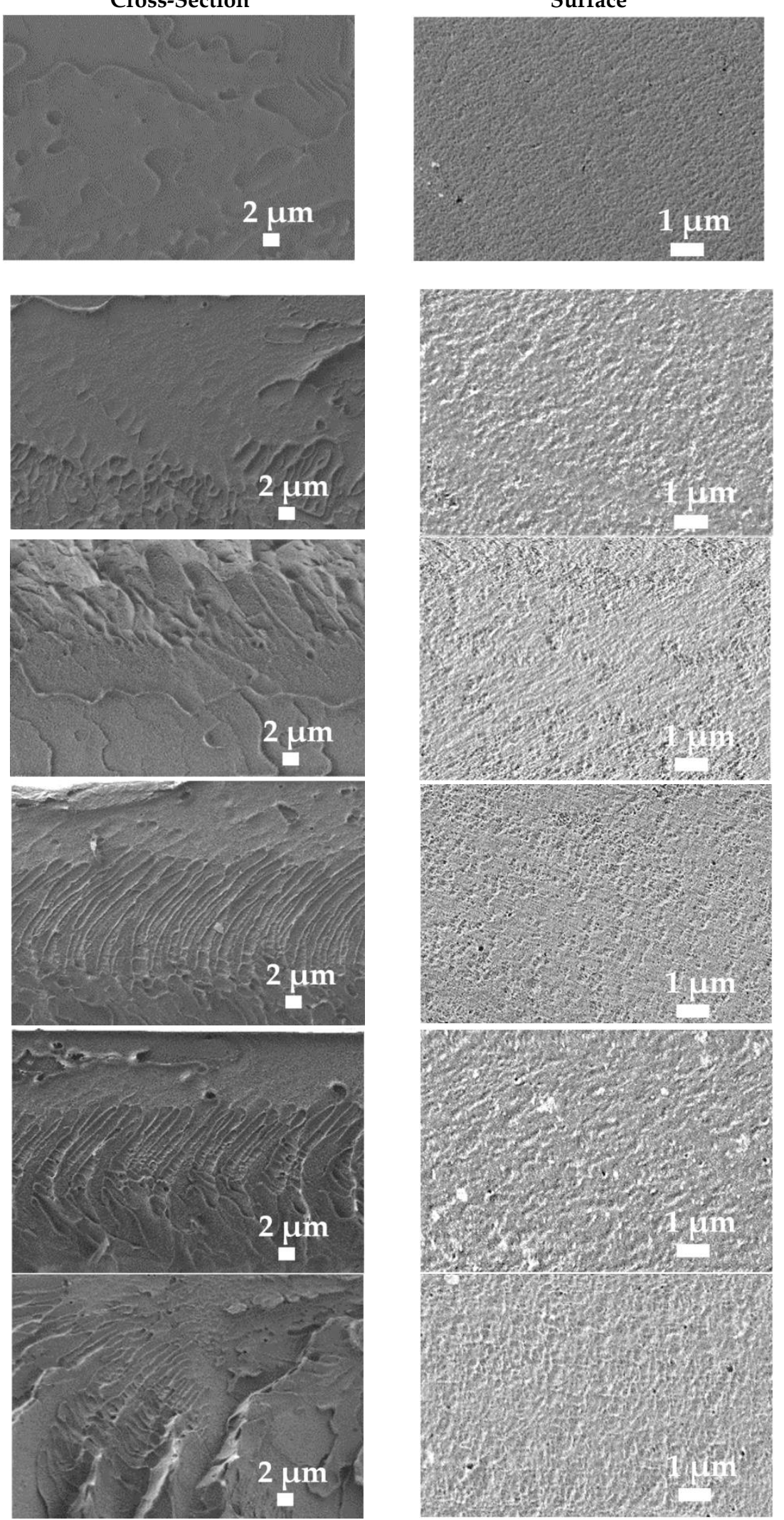

Figure 8. SEM cross-sectional and surface micrographs of the dense (a) PPO, (b) PPO/GO (0.1\%), (c) PPO/GO (0.3\%), (d) PPO/GO (0.5\%), (e) PPO/GO (0.7\%), and (f) PPO/GO (0.9\%) membranes. 
(a)
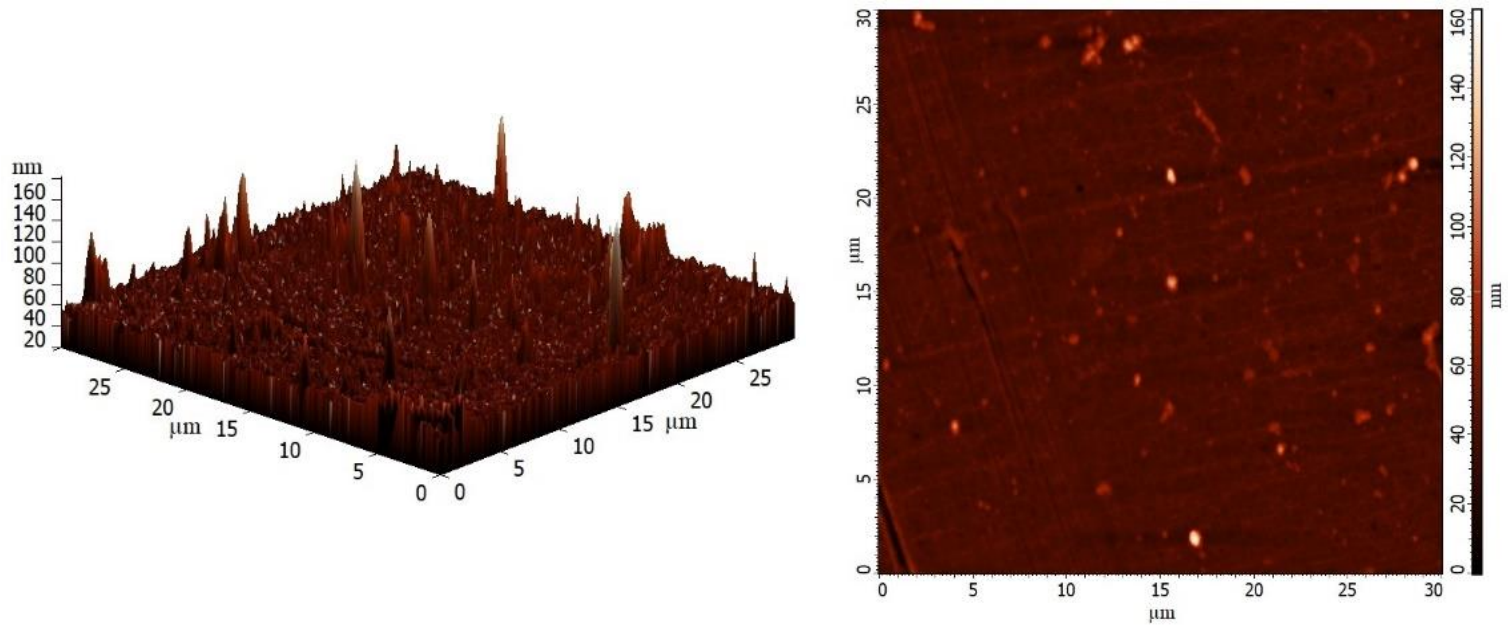

(b)
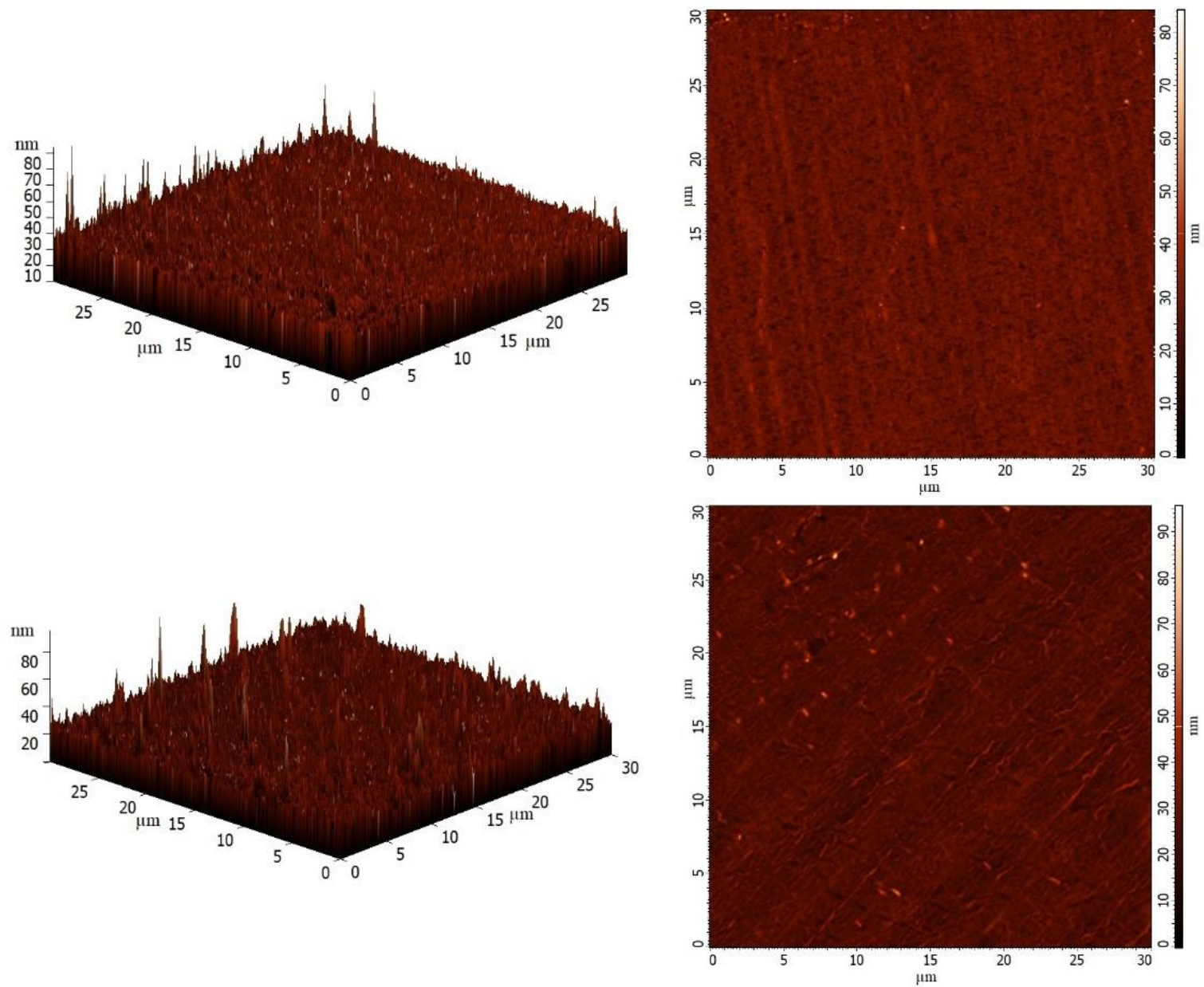

Figure 9. Cont 
(d)
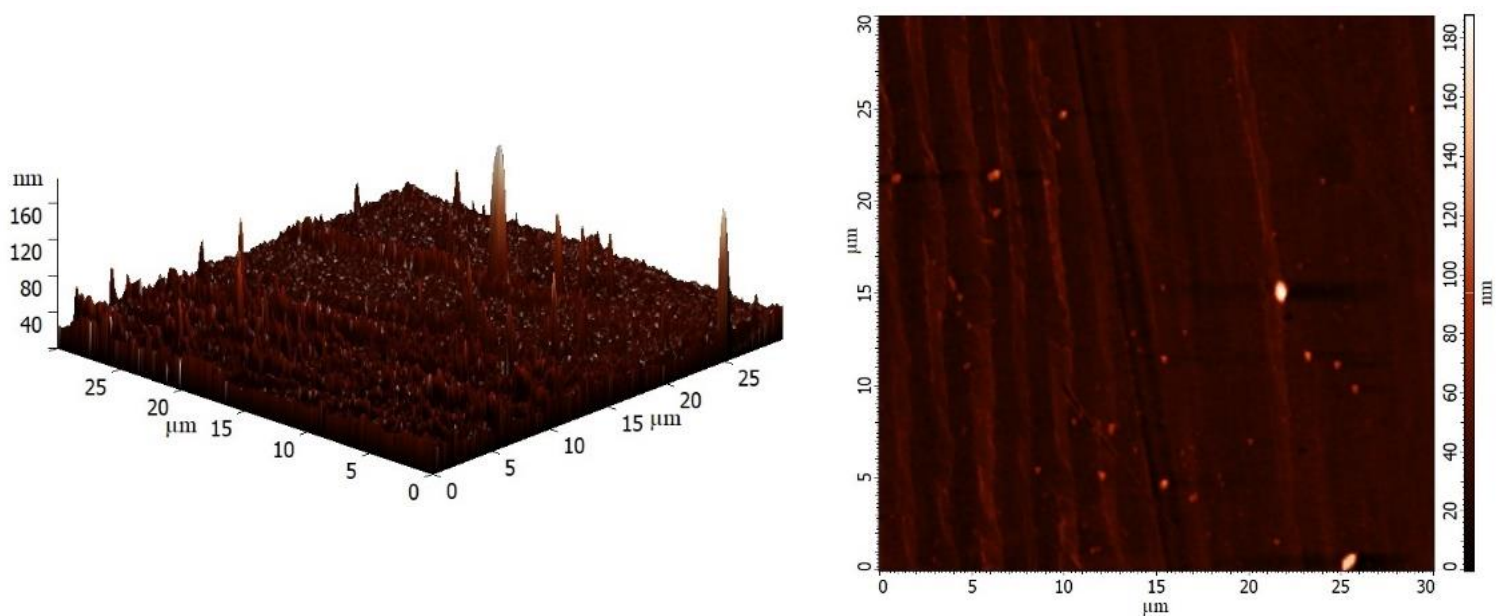

(e)
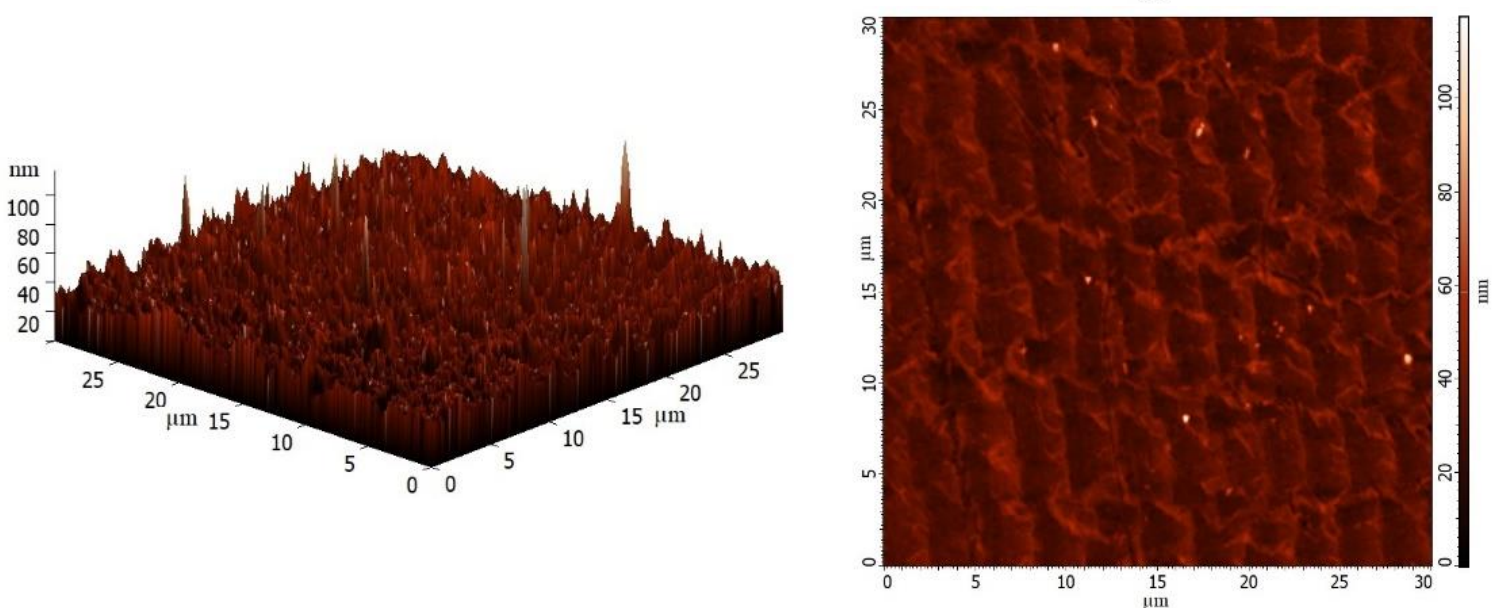

$(\mathbf{f})$
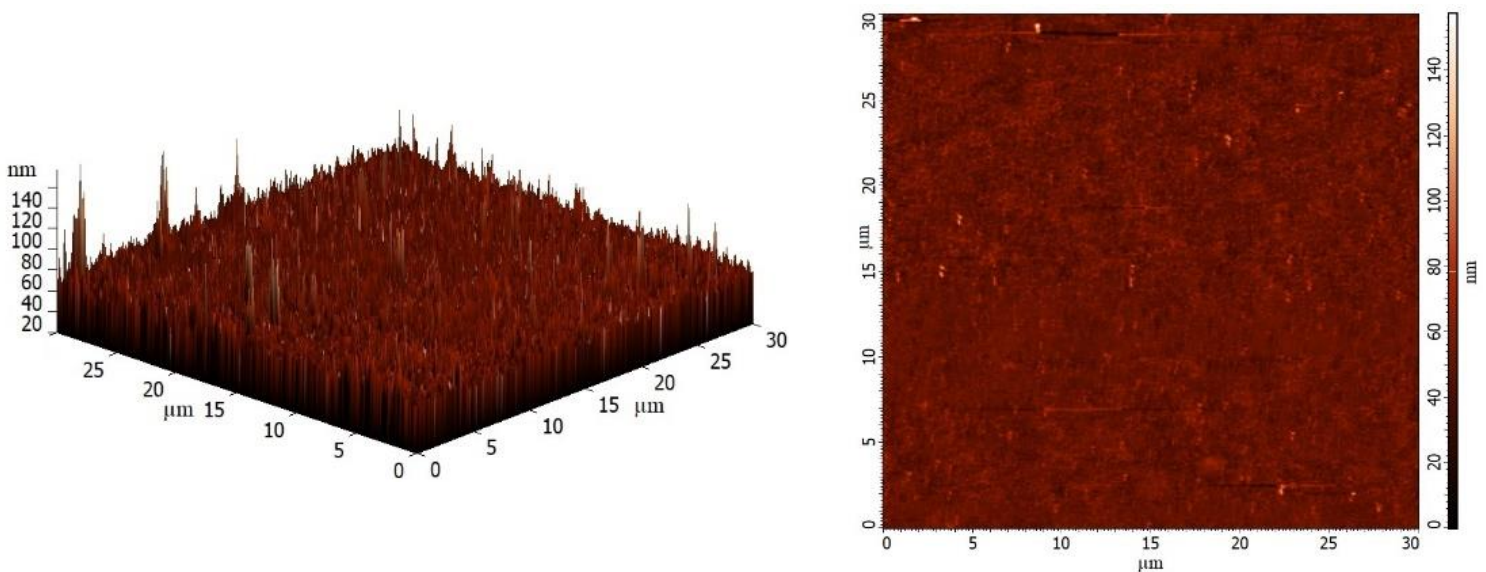

Figure 9. AFM images of the dense (a) PPO, (b) PPO/GO (0.1\%), (c) PPO/GO (0.3\%), (d) PPO/GO $(0.5 \%),(\mathbf{e}) \mathrm{PPO} / \mathrm{GO}(0.7 \%)$, and (f) PPO/GO (0.9\%) membranes.

The surface of all membranes was demonstrated to have a typical nodule structure. The AFM data corroborated the surface SEM micrographs that the introduction of the GO particles into PPO resulted in higher roughness. The GO particles were observed on the surface for modified membranes, and their amount increased with an increase in modifier concentration with respect to the PPO weight. Based on AFM, the surface roughness parameters in terms of average roughness (Ra) and root-mean-squared roughness (Rq) were calculated (Table 1). 
Table 1. Surface roughness parameters of the dense PPO and PPO/GO membranes.

\begin{tabular}{ccc}
\hline \multirow{2}{*}{ Membrane } & \multicolumn{2}{c}{ Surface Parameters } \\
\cline { 2 - 3 } & $\mathbf{R a}, \mathbf{n m}$ & $\mathbf{R q}, \mathbf{n m}$ \\
\hline $\mathrm{PPO}$ & $3.8 \pm 0.2$ & $6.6 \pm 0.2$ \\
$\mathrm{PPO} / \mathrm{GO}(0.1 \%)$ & $3.3 \pm 0.5$ & $5.9 \pm 0.5$ \\
$\mathrm{PPO} / \mathrm{GO}(0.3 \%)$ & $3.5 \pm 0.5$ & $5.8 \pm 0.5$ \\
$\mathrm{PPO} / \mathrm{GO}(0.5 \%)$ & $5.2 \pm 0.5$ & $7.2 \pm 0.5$ \\
$\mathrm{PPO} / \mathrm{GO}(0.7 \%)$ & $5.5 \pm 0.5$ & $7.5 \pm 0.5$ \\
$\mathrm{PPO} / \mathrm{GO}(0.9 \%)$ & $5.7 \pm 0.5$ & $7.9 \pm 0.5$ \\
\hline
\end{tabular}

The data in Table 1 demonstrate that the PPO/GO $(0.1 \%)$ and PPO/GO (0.3\%) membranes have comparatively the same values of surface roughness within the margin of error, compared to the pristine PPO membrane due to a low GO content in the polymer matrix. Notably, the difference in the surface roughness values ( $\mathrm{Ra}$ and $\mathrm{Rq}$ ) of these membranes (PPO, PPO/GO $(0.1 \%)$, and PPO/GO $(0.3 \%)$ ) did not exceed even $0.8 \mathrm{~nm}$ [53]. Only the introduction of GO above $0.5 \mathrm{wt} . \%$ significantly increased surface parameters, making it possible to clearly evaluate the contribution of the modification to the change in the membrane surface. The PPO/GO (0.9\%) membrane has the highest surface roughness characteristics $(\mathrm{Ra}=5.7 \mathrm{~nm}$ and $\mathrm{Rq}=7.9 \mathrm{~nm})$ compared with other membranes (also confirmed by SEM, Figure $8 \mathrm{f}$ ), indicating the largest number of GO particle agglomeration on the membrane surface. The increase in surface roughness provides a large effective surface area to contact with the feed components, which is one of the factors resulting in the facilitated sorption and faster penetration of substances. This results in improved modified membrane permeability, which is in agreement with the pervaporation data (Figure 3a) [51].

Mass transfer in pervaporation through a membrane is described by the "solubilitydiffusion" mechanism, where the main stages are selective sorption of the feed components on the membrane and their diffusion through the membrane (rate defining stage). In this regard, parameters such as a swelling degree in water and EG and contact angles of water for membranes were investigated to estimate the component transport through the membranes and to assess the changes in the hydrophilic-hydrophobic properties [54] during modification of the PPO-based membrane (Table 2).

Table 2. Contact angles of water and swelling degrees of the dense PPO and PPO/GO membranes.

\begin{tabular}{cccc}
\hline \multirow{2}{*}{ Membrane } & $\begin{array}{c}\text { Contact Angle of } \\
\text { Water, }\end{array}$ & \multicolumn{2}{c}{ Swelling Degree, \% } \\
\cline { 3 - 4 } & $89 \pm 2$ & Water & Ethylene Glycol \\
\hline PPO & $89 \pm 2$ & 1.4 & 3.4 \\
PPO/GO $(0.1 \%)$ & $87 \pm 2$ & 1.8 & 3.5 \\
PPO/GO $(0.3 \%)$ & $86 \pm 2$ & 2.7 & 3.5 \\
PPO/GO $(0.5 \%)$ & $85 \pm 2$ & 3.5 & 4.4 \\
PPO/GO $(0.7 \%)$ & $83 \pm 2$ & 6.4 & 7.1 \\
PPO/GO $(0.9 \%)$ & 6.6 & 7.7 \\
\hline
\end{tabular}

PPO is a relatively hydrophobic polymer with a high contact angle of water. The contact angle of water for the pristine PPO membrane was equal to $89^{\circ}$; the corroborating values for the PPO membrane were obtained in the previous studies $[23,41,43]$. The value of contact angle of water for the PPO/GO $(0.1 \%)$ membrane was equal to the PPO membrane $\left(89 \pm 2^{\circ}\right)$. For the PPO/GO $(0.3 \%)$ membrane, the contact angle of water slightly decreased to $87^{\circ}$, and the difference with the PPO membrane in the value of the contact angle did not exceed $2^{\circ}$, which was due to the low modifier contents in the membrane. It is also worth noting that these concentrations did not change significantly the morphology and the surface parameters of the PPO membrane (confirmed by SEM and AFM data, Figures 8 and 9). The contact angle of water for the modified membranes with over $0.5 \mathrm{wt} . \%$ GO decreased considerably with an increase in the modifier content in 
the PPO matrix, indicating surface hydrophilization. The introduction of GO-associated functional groups improved the hydrophilic properties of the PPO membrane because of the migration of hydrophilic (oxygen-containing) groups to the top of the membrane surface, causing improved permeation flux and water permeance for the modified membranes (Figure 3a,c) [55,56]. The water contact angle values are in agreement with the surface roughness parameters (Table 1). The same effect of increasing the surface roughness and decreasing the contact angle values was previously observed for hydrophobic polyimide hollow fiber membranes and polyamide/poly(acrylonitrile) (PAN) membranes modified by GO $[57,58]$. Based on the swelling experiments in water and EG, the sorption and diffusion properties of the PPO-based membranes were determined. The introduction of GO into the PPO matrix enhanced the swelling of the membranes in both components. Additionally, the swelling increased with the rise in the modifier content (Table 2). This effect could be associated with the structure of GO possessing oxygen-containing groups, providing a higher affinity of the modified membranes to polar compounds compared to the pristine PPO matrix [24]. Mass transfer of the components of the separated mixture largely depends on the affinity of the penetrants to the membrane, and an increase in the swelling of the membranes in water and EG increased the permeability of the membranes, especially with the higher GO content in the PPO matrix (Figure 3a) [25]. It is also worth noting that the swelling in EG for the PPO-based membranes was slightly higher than that in water (Table 2). This indicates the enhanced membrane interaction with EG, rather than with water, and the formation of transport channels for the water penetration [41].

The thermal stability of the PPO-based membranes was investigated by TGA. Figure 10 demonstrates thermogravimetric (TG) curves (weight loss) of the samples under heating from 30 to $950{ }^{\circ} \mathrm{C}$.

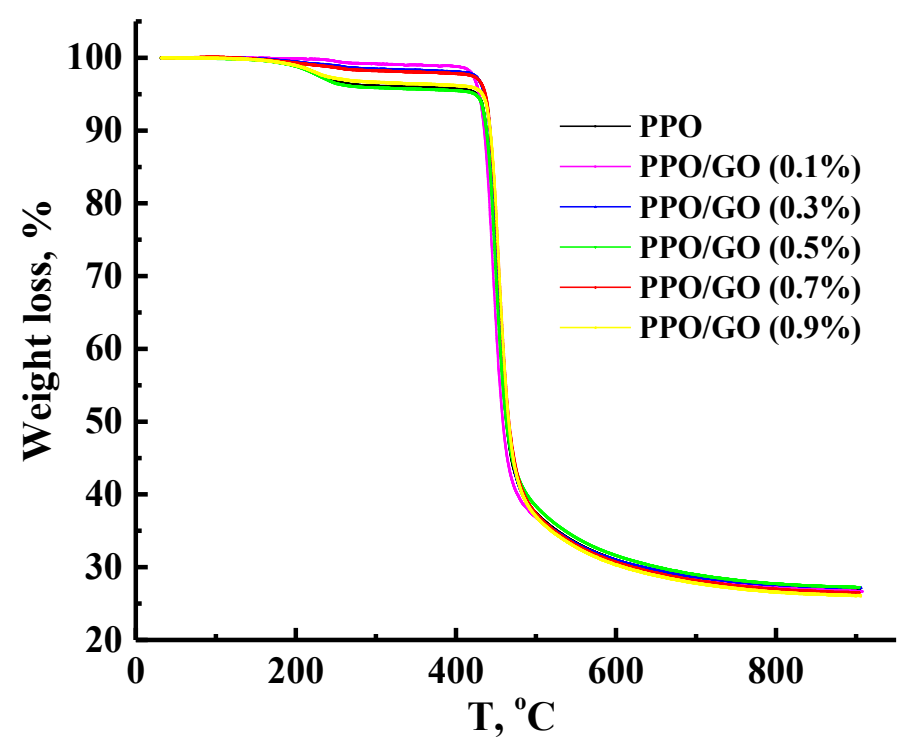

Figure 10. TG curves for the dense PPO and PPO/GO membranes.

It was shown that all PPO-based membranes were heat-resistant over a wide temperature range as was demonstrated previously [44]. The TG patterns for the membranes based on pristine PPO and the GO composites are similar and demonstrate two stages of weight loss. In the first stage up to $400{ }^{\circ} \mathrm{C}$, there is a relatively small weight loss of up to $4 \mathrm{wt}$ \% for all membranes. This observation is connected to the residual solvent evaporation and the elimination of low molecular weight impurities [44]. The second range refers to the area from $400{ }^{\circ} \mathrm{C}$. The weight loss of up to $70 \mathrm{wt}$. \% is related to the decomposition of polymer chains. The residual mass of all samples was $\sim 27 \mathrm{wt} \%$. It should be also noted that GO is highly heat-resistant with combustion temperature in the range of $550-616^{\circ} \mathrm{C}$, depending on the particle size [59]. Based on the TGA data, no changes in the TG curves 
were observed in the membranes, possibly due to the low level of GO concentration in the membrane matrix. The modification did not significantly affect the thermal stability of the PPO-based membranes.

\subsubsection{The Study of the Supported Membranes}

To confirm suitable adhesion and to evaluate the thickness and the surface parameters of the selective dense layer, deposited onto the porous MFFC substrate, the developed supported membranes were investigated by SEM, AFM, and contact angle measurements. It was found that the values of contact angles of water for the supported PPO/MFFC and $\mathrm{PPO} / \mathrm{GO}(0.7 \%) / \mathrm{MFFC}$ membranes were equal to those for the dense membranes $\left(89 \pm 2^{\circ}\right.$ and $85 \pm 2^{\circ}$, respectively, Table 2), which also confirmed the uniformity and continuity of the thin selective layer on the porous MMFC substrate. The SEM micrographs and AFM images of the PPO/MFFC and PPO/GO (0.7\%)/MFFC membranes are presented in Figure 11.

(a)

(b)

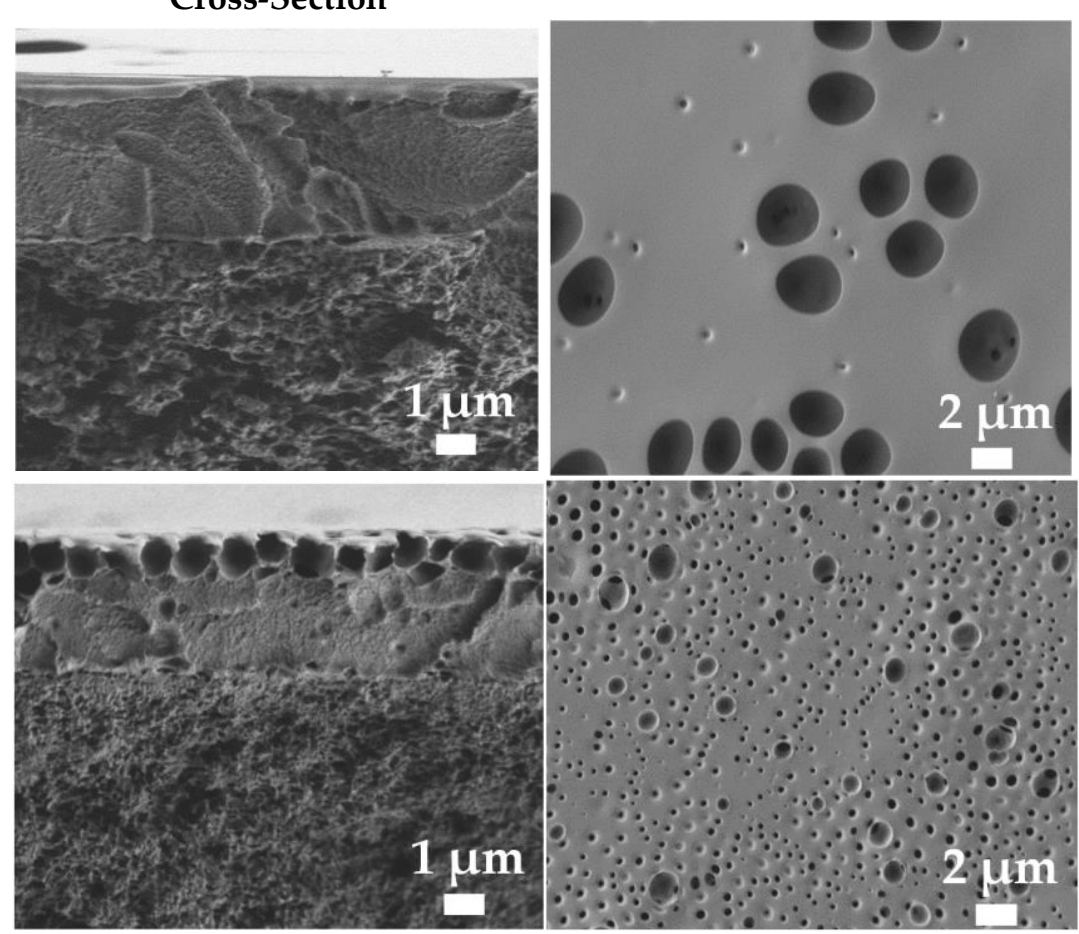

\section{Surface}
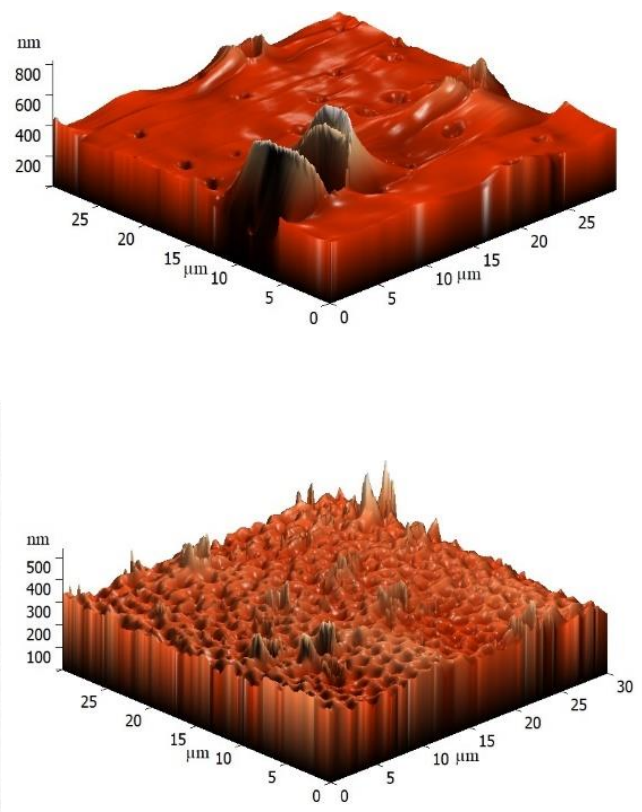

Figure 11. SEM surface and cross-sectional micrographs and AFM images of the supported (a) $\mathrm{PPO} / \mathrm{MFFC}$ and (b) PPO/GO (0.7\%)/MFFC membranes.

The cross-sectional SEM micrographs of the supported membranes clearly demonstrate two regions: (1) the porous MFFC substrate, and (2) a thin, dense selective layer based on the PPO and PPO/GO $(0.7 \%)$ composite. The thickness of the thin, dense selective layer based on the PPO or PPO/GO (0.7\%) composite was determined to be $3 \pm 0.2 \mu \mathrm{m}$. Continuous and homogeneous adhesion of the thin, dense layers to the surface of the porous MFFC substrate is also observed. There was no leakage of the polymer solution and composite into the pores of the substrate. Notably, the supported membranes had rounded cavities on the surface of the thin selective layer, as the dense membranes did (Figure 8). These cavities were not hollow (confirmed by SEM cross-sectional micrographs) and they increased in number with a decrease in size, when GO was introduced into the PPO matrix. The same effect of the formation of additional surface cavities was observed during PPO modification with heteroarm star-shaped macromolecules and ionic liquid in the works $[25,47]$. This effect, together with the hydrophilization of the membrane surface during the modification, may contribute to increased permeability of the modified membrane (Figure 4). Based on 
AFM images, the average roughness $(\mathrm{Ra})$ and root-mean-squared roughness $(\mathrm{Rq})$ for the supported membranes were calculated (Table 3).

Table 3. Surface roughness parameters of the supported PPO/MFFC and PPO/GO (0.7\%)/MFFC membranes.

\begin{tabular}{ccc}
\hline \multirow{2}{*}{ Membrane } & \multicolumn{2}{c}{ Surface Parameters } \\
\cline { 2 - 3 } & $\mathbf{R a}, \mathbf{n m}$ & $\mathbf{R q}, \mathbf{n m}$ \\
\hline PPO/MFFC & 33.5 & 68.1 \\
$\mathrm{PPO} / \mathrm{GO}(0.7 \%) / \mathrm{MFFC}$ & 54.6 & 82.7 \\
\hline
\end{tabular}

It was found that the deposition of the thin PPO and PPO/GO (0.7\%) layers onto a porous MFFC substrate led to a significant increase in the surface roughness compared to the dense membranes (Table 1$)$. However, the surface parameters of the PPO/GO $(0.7 \%) /$ MFFC membrane are significantly higher compared to the PPO/MFFC membrane, due to the presence of GO nanoparticles in the thin selective layer. The increased surface roughness of the modified membrane can also be attributed to the formation of a larger number of cavities on the surface, causing the rise in permeability for the modified membrane.

\subsection{Membrane Performance Comparison in Pervaporation Separation of EG/Water Mixture}

The performance of polymeric membranes described in the literature for pervaporation dehydration of EG was compared with the developed dense and supported membrane based on the PPO/GO (0.7\%) composite in terms of permeation flux and separation factor (Table 4).

The developed dense PPO/GO (0.7\%) membrane had higher permeation flux in pervaporation dehydration of EG (10 wt.\% water), even under the separation at room temperature, compared to the membranes presented in the works $[7,23]$. However, the separation factor (4491) was lower compared to the PPO/heteroarm stars with $\mathrm{C}_{60}$ (5\%) center membrane [23]. The polybenzimidazole/polyetherimide dual-layer hollow fiber membrane had increased permeation flux and decreased separation factor compared to the dense PPO/GO (0.7\%) membrane, but its transport properties were measured at a much higher experimental temperature $\left(60^{\circ} \mathrm{C}\right)$ [13]. As for the developed supported PPO/GO $(0.7 \%) /$ MFFC membrane, it has an enhanced separation factor (4082) compared to all presented supported membranes, including the commercial ones [61]. Furthermore, it should be noted that permeation flux for the PPO/GO (0.7\%)/MFFC membrane is lower compared to the membranes described in the works $[10,11,60,61]$, but this is related to the difference in the temperature of the experiment. The permeation flux of the developed membrane can be significantly increased by the use of higher temperatures; the membrane's high thermal stability was confirmed by TGA (Figure 10).

Thus, it was demonstrated that supported PPO/GO $(0.7 \%) /$ MFFC membrane (modified with $0.7 \mathrm{wt} . \% \mathrm{GO}$ ) had the optimal transport characteristics in pervaporation dehydration of EG compared with literature-described polymeric membranes, and is promising for application in industrial EG regeneration processes. 
Table 4. Comparison of transport properties for the membranes in pervaporation dehydration of ethylene glycol (10 wt.\% water).

\begin{tabular}{|c|c|c|c|c|}
\hline Membrane & Temperature, ${ }^{\circ} \mathrm{C}$ & $\begin{array}{l}\text { Permeation Flux, } \\
\mathrm{g} /\left(\mathrm{m}^{2} \cdot \mathrm{h}\right)\end{array}$ & $\begin{array}{l}\text { Separation } \\
\text { Factor }(\beta)\end{array}$ & Reference \\
\hline \multicolumn{5}{|c|}{ Dense membranes } \\
\hline $\mathrm{PPO} / \mathrm{GO}(0.7 \%)$ & 22 & 78 & 4491 & This study \\
\hline PIM-1 (polymer of intrinsic microporosity) & 30 & 51 & 39 & [7] \\
\hline PPO/heteroarm stars with $\mathrm{C}_{60}$ center (5\%) & 50 & 21 & 11,240 & [23] \\
\hline $\begin{array}{l}\text { Polybenzimidazole/polyetherimide } \\
\text { dual-layer hollow fiber membrane }\end{array}$ & 60 & 115 & 1763 & [13] \\
\hline \multicolumn{5}{|c|}{ Supported membranes } \\
\hline PPO/GO (0.7\%)/MFFC & 22 & 180 & 4082 & This study \\
\hline $\begin{array}{l}\text { Polyethylenimine-poly(acrylic acid) } \\
\text { (PEI/PAA) complex/PA }\end{array}$ & 22 & 12 & 415 & [12] \\
\hline PVA/buckypaper & 30 & 26 & 802 & \multirow[b]{2}{*}{ [4] } \\
\hline $\begin{array}{l}\text { 1-butyl-3-methylimidazolium } \\
\text { tetrafluoroborate-PVA }(70 / 30) / \text { buckypaper }\end{array}$ & 30 & 102 & 1014 & \\
\hline Chitosan/PS & 35 & 300 & 104 & [10] \\
\hline PVA/PS & 60 & 360 & 987 & {$[60]$} \\
\hline Polyelectrolyte complex/GO (3 wt.\%)/PS & 60 & 961 & 1191 & [11] \\
\hline GFT1001 (PVA/PAN) & 75 & 244 & 1116 & \multirow{4}{*}[61]{} \\
\hline GFT1000 (PVA/PAN) & 75 & 56 & 141 & \\
\hline GFT1510 (PVA/PAN) & 75 & 1700 & 591 & \\
\hline DEG167 (PVA/PAN) & 75 & 500 & 991 & \\
\hline
\end{tabular}

\section{Conclusions}

In this study, novel dense and supported mixed matrix membranes based on poly(2,6dimethyl-1,4-phenylene oxide) modified with graphene oxide nanoparticles were developed for improved pervaporation dehydration of ethylene glycol. The introduction of graphene oxide (0.1-0.9 wt.\%) into the PPO matrix improved permeation flux of the dense membranes with a slight decrease in selectivity with respect to water, compared to the unfilled PPO membrane in pervaporation dehydration of EG in a wide concentration range (10-90 wt.\% water). These observations were related to the changes in the structure and physicochemical properties: the formation of a more amorphous structure of the membrane, rougher inner and surface morphology, and surface hydrophilization (confirmed by various techniques-FTIR, NMR, SEM, AFM, swelling and contact angle measurements). The dense PPO/GO (0.7\%) membrane had the optimal transport characteristics: the highest permeation flux of $78-470 \mathrm{~g} /\left(\mathrm{m}^{2} \cdot \mathrm{h}\right)$, and $99.3-96.2 \mathrm{wt} . \%$ water in the permeate in pervaporation dehydration of EG (10-90 wt.\% water). To improve the permeability of this dense membrane for promising industrial applications, the supported membrane consisting of a thin selective layer based on the PPO/GO $(0.7 \%)$ composite deposited onto the porous MFFC substrate was developed. This modified supported PPO/GO (0.7\%)/MFFC membrane demonstrated ca. 15 times higher permeation flux, maintaining high selectivity (99.8-99.6 wt.\% water in the permeate), compared to the dense PPO membrane in pervaporation dehydration of EG (10-30 wt.\% water). Thus, the supported PPO/GO (0.7\%)/MFFC membrane is promising for industrial application in EG dehydration processes. 


\begin{abstract}
Author Contributions: Conceptualization, M.D.; methodology, K.S., N.S. and A.P.; investigation, M.D., A.C., V.L. and A.M.; data curation, M.D.; writing-original draft preparation, M.D.; writingreview and editing, M.D., A.P. and N.S.; visualization, M.D. and A.P.; supervision, M.D.; project administration, M.D.; funding acquisition, M.D. All authors have read and agreed to the published version of the manuscript.
\end{abstract}

Funding: This research was funded by the Russian Science Foundation, grant number 21-73-00043.

Institutional Review Board Statement: Not applicable.

Informed Consent Statement: Not applicable.

Acknowledgments: The experimental work was facilitated by the equipment from the Resource Centers for Nanotechnology, Magnetic Resonance, X-ray Diffraction Studies, Cryogenic Department, Thermogravimetric and Calorimetric Research Centre, Chemical Analysis and Materials Research Centre, and Centre "Nanofabrication of Photoactive Materials (Nanophotonics)" at the St. Petersburg State University.

Conflicts of Interest: The authors declare no conflict of interest.

\title{
References
}

1. Guo, R.; Hu, C.; Li, B.; Jiang, Z. Pervaporation separation of ethylene glycol/water mixtures through surface crosslinked PVA membranes: Coupling effect and separation performance analysis. J. Memb. Sci. 2007, 289, 191-198. [CrossRef]

2. Huang, R.Y.M.; Shao, P.; Feng, X.; Anderson, W.A. Separation of Ethylene Glycol-Water Mixtures Using Sulfonated Poly(ether ether ketone) Pervaporation Membranes: Membrane Relaxation and Separation Performance Analysis. Ind. Eng. Chem. Res. 2002, 41, 2957-2965. [CrossRef]

3. Halakoo, E.; Feng, X. Self-assembled membranes from polyethylenimine and graphene oxide for pervaporation dehydration of ethylene glycol. J. Memb. Sci. 2020, 616, 118583. [CrossRef]

4. Ong, Y.T.; Tan, S.H. Synthesis of the novel symmetric buckypaper supported ionic liquid membrane for the dehydration of ethylene glycol by pervaporation. Sep. Purif. Technol. 2015, 143, 135-145. [CrossRef]

5. Wu, J.-K.; Yin, M.-J.; Han, W.; Wang, N.; An, Q.-F. Development of high-performance polyelectrolyte-complex-nanoparticle-based pervaporation membranes via convenient tailoring of charged groups. J. Mater. Sci. 2020, 55, 12607-12620. [CrossRef]

6. Penkova, A.V.; Acquah, S.F.; Piotrovskiy, L.B.; Markelov, D.A.; Semisalova, A.S.; Kroto, H.W. Fullerene derivatives as nanoadditives in polymer composites. Russ. Chem. Rev. 2017, 86, 530-566. [CrossRef]

7. Wu, X.M.; Guo, H.; Soyekwo, F.; Zhang, Q.G.; Lin, C.X.; Liu, Q.L.; Zhu, A.M. Pervaporation Purification of Ethylene Glycol Using the Highly Permeable PIM-1 Membrane. J. Chem. Eng. Data 2016, 61, 579-586. [CrossRef]

8. Shahverdi, M.; Baheri, B.; Rezakazemi, M.; Motaee, E.; Mohammadi, T. Pervaporation study of ethylene glycol dehydration through synthesized (PVA-4A)/polypropylene mixed matrix composite membranes. Polym. Eng. Sci. 2013, 53, 1487-1493. [CrossRef]

9. Hu, S.Y.; Zhang, Y.; Lawless, D.; Feng, X. Composite membranes comprising of polyvinylamine-poly(vinyl alcohol) incorporated with carbon nanotubes for dehydration of ethylene glycol by pervaporation. J. Memb. Sci. 2012, 417-418, 34-44. [CrossRef]

10. Feng, X. Pervaporation with chitosan membranes. I. Separation of water from ethylene glycol by a chitosan/polysulfone composite membrane. J. Memb. Sci. 1996, 116, 67-76. [CrossRef]

11. Wu, J.-K.; Ye, C.-C.; Zhang, W.-H.; Wang, N.-X.; Lee, K.-R.; An, Q.-F. Construction of well-arranged graphene oxide/polyelectrolyte complex nanoparticles membranes for pervaporation ethylene glycol dehydration. J. Memb. Sci. 2019, 577, 104-112. [CrossRef]

12. Zhang, Y.; Rhim, J.W.; Feng, X. Improving the stability of layer-by-layer self-assembled membranes for dehydration of alcohol and diol. J. Memb. Sci. 2013, 444, 22-31. [CrossRef]

13. Wang, Y.; Chung, T.S.; Neo, B.W.; Gruender, M. Processing and engineering of pervaporation dehydration of ethylene glycol via dual-layer polybenzimidazole (PBI)/polyetherimide (PEI) membranes. J. Memb. Sci. 2011, 378, 339-350. [CrossRef]

14. Villaluenga, J.P.G.; Godino, P.; Khayet, M.; Seoane, B.; Mengual, J.I. Pervaporation of Alcohols and Methyl t ert -Butyl Ether through a Dense Poly(2,6-dimethyl-1,4-phenylene oxide) Membrane. Ind. Eng. Chem. Res. 2004, 43, 2548-2555. [CrossRef]

15. Polotskaya, G.; Biryulin, Y.; Pientka, Z.; Brozova, L.; Bleha, M. Transport Properties of Fullerene-Polyphenylene Oxide Homogeneous Membranes. Fuller. Nanotub. Carbon Nanostruct. 2005, 12, 365-369. [CrossRef]

16. Tyan, N.S.; Polotskaya, G.A.; Meleshko, T.K.; Yakimansky, A.V.; Pientka, Z. Influence of the Molecular Polyimide Brush on the Gas Separation Properties of Polyphenylene Oxide. Russ. J. Appl. Chem. 2019, 92, 360-366. [CrossRef]

17. Pulyalina, A.; Rostovtseva, V.; Polotskaya, G.; Vinogradova, L.; Zoolshoev, Z.; Simonova, M.; Hairullin, A.; Toikka, A.; Pientka, Z. Hybrid macromolecular stars incorporated poly(phenylene oxide) membranes: Organization, physical, and gas separation properties. Polymer 2019, 172, 355-364. [CrossRef]

18. Jung, B.; Yoon, J.K.; Kim, B.; Rhee, H.-W. Effect of molecular weight of polymeric additives on formation, permeation properties and hypochlorite treatment of asymmetric polyacrylonitrile membranes. J. Memb. Sci. 2004, 243, 45-57. [CrossRef] 
19. Polotskaya, G.A.; Penkova, A.V.; Toikka, A.M. Fullerene-containing polyphenylene oxide membranes for pervaporation. Desalination 2006, 200, 400-402. [CrossRef]

20. Penkova, A.; Polotskaya, G.; Toikka, A. Pervaporation composite membranes for ethyl acetate production. Chem. Eng. Process. Process Intensif. 2015, 87, 81-87. [CrossRef]

21. Polotskaya, G.; Pulyalina, A.; Lebedev, V.; Török, G.; Rudakova, D.; Vinogradova, L. Novel view at hybrid membranes containing star macromolecules using neutron scattering and pervaporation dehydration of acetic acid. Mater. Des. $2020,186,108352$. [CrossRef]

22. Moulik, S.; Kumar, K.P.; Bohra, S.; Sridhar, S. Pervaporation performance of PPO membranes in dehydration of highly hazardous mmh and udmh liquid propellants. J. Hazard. Mater. 2015, 288, 69-79. [CrossRef] [PubMed]

23. Rostovtseva, V.; Pulyalina, A.; Rudakova, D.; Vinogradova, L.; Polotskaya, G. Strongly Selective Polymer Membranes Modified with Heteroarm Stars for the Ethylene Glycol Dehydration by Pervaporation. Membranes 2020, 10, 86. [CrossRef] [PubMed]

24. Polotskaya, G.A.; Krasnopeeva, E.L.; Kalyuzhnaya, L.M.; Saprykina, N.N.; Vinogradova, L.V. Mixed matrix membranes with hybrid star-shaped macromolecules for mono- and dihydric alcohols pervaporation. Sep. Purif. Technol. 2015, 143, 192-200. [CrossRef]

25. Polotskaya, G.A.; Lebedev, V.T.; Pulyalina, A.Y.; Vinogradova, L.V. Structure and transport properties of pervaporation membranes based on polyphenylene oxide and heteroarm star polymers. Pet. Chem. 2016, 56, 920-930. [CrossRef]

26. Dreyer, D.R.; Park, S.; Bielawski, C.W.; Ruoff, R.S. The chemistry of graphene oxide. Chem. Soc. Rev. 2010, 39, 228-240. [CrossRef]

27. Ashtiani, S.; Khoshnamvand, M.; Shaliutina-Kolešová, A.; Bouša, D.; Sofer, Z.; Friess, K. Co0·5Ni0.5FeCrO4 spinel nanoparticles decorated with UiO-66-based metal-organic frameworks grafted onto GO and O-SWCNT for gas adsorption and water purification. Chemosphere 2020, 255, 126966. [CrossRef]

28. Mahmoud, K.A.; Mansoor, B.; Mansour, A.; Khraisheh, M. Functional graphene nanosheets: The next generation membranes for water desalination. Desalination 2015, 356, 208-225. [CrossRef]

29. Chong, J.Y.; Wang, B.; Mattevi, C.; Li, K. Dynamic microstructure of graphene oxide membranes and the permeation flux. J. Memb. Sci. 2018, 549, 385-392. [CrossRef]

30. Sun, P.; Wang, K.; Zhu, H. Recent Developments in Graphene-Based Membranes: Structure, Mass-Transport Mechanism and Potential Applications. Adv. Mater. 2016, 28, 2287-2310. [CrossRef]

31. Ma, J.; Ping, D.; Dong, X. Recent Developments of Graphene Oxide-Based Membranes: A Review. Membranes 2017, 7, 52. [CrossRef]

32. Guan, K.; Liu, G.; Matsuyama, H.; Jin, W. Graphene-based membranes for pervaporation processes. Chin. J. Chem. Eng. 2020, 28, 1755-1766. [CrossRef]

33. Hummers, W.S.; Offeman, R.E. Preparation of Graphitic Oxide. J. Am. Chem. Soc. 1958, 80, 1339. [CrossRef]

34. Dmitrenko, M.; Liamin, V.; Lahderanta, E.; Ermakov, S.; Penkova, A. Mixed matrix membranes based on sodium alginate modified by fullerene derivatives with L-amino acids for pervaporation isopropanol dehydration. J. Mater. Sci. 2021. [CrossRef]

35. Kuzminova, A.; Dmitrenko, M.; Zolotarev, A.; Korniak, A.; Poloneeva, D.; Selyutin, A.; Emeline, A.; Yushkin, A.; Foster, A.; Budd, P.; et al. Novel Mixed Matrix Membranes Based on Polymer of Intrinsic Microporosity PIM-1 Modified with Metal-Organic Frameworks for Removal of Heavy Metal Ions and Food Dyes by Nanofiltration. Membranes 2021, 12, 14. [CrossRef]

36. Mural, P.K.S.; Madras, G.; Bose, S. Polymeric membranes derived from immiscible blends with hierarchical porous structures, tailored bio-interfaces and enhanced flux: Potential and key challenges. Nano-Struct. Nano-Objects 2018, 14, 149-165. [CrossRef]

37. Dmitrenko, M.; Liamin, V.; Kuzminova, A.; Mazur, A.; Lahderanta, E.; Ermakov, S.; Penkova, A. Novel Mixed Matrix Sodium Alginate-Fullerenol Membranes: Development, Characterization, and Study in Pervaporation Dehydration of Isopropanol. Polymers 2020, 12, 864. [CrossRef] [PubMed]

38. Penkova, A.V.; Dmitrenko, M.E.; Ermakov, S.S.; Toikka, A.M.; Roizard, D. Novel green PVA-fullerenol mixed matrix supported membranes for separating water-THF mixtures by pervaporation. Environ. Sci. Pollut. Res. 2017, 25, 20354-20362. [CrossRef] [PubMed]

39. Baker, R.W. Membrane Technology and Applications; McGraw-Hill: New York, NY, USA, 2000.

40. Baker, R.W.; Wijmans, J.G.; Huang, Y. Permeability, permeance and selectivity: A preferred way of reporting pervaporation performance data. J. Memb. Sci. 2010, 348, 346-352. [CrossRef]

41. Polotskaya, G.A.; Penkova, A.V.; Toikka, A.M.; Pientka, Z.; Brozova, L.; Bleha, M. Transport of small molecules through polyphenylene oxide membranes modified by fullerene. Sep. Sci. Technol. 2007, 42, 333-347. [CrossRef]

42. Dmitrenko, M.E.; Penkova, A.V.; Atta, R.R.; Zolotarev, A.A.; Plisko, T.V.; Mazur, A.S.; Solovyev, N.D.; Ermakov, S.S. The development and study of novel membrane materials based on polyphenylene isophthalamide-Pluronic F127 composite. Mater. Des. 2019, 165, 107596. [CrossRef]

43. Khayet, M.; Villaluenga, J.P.G.; Valentin, J.L.; López-Manchado, M.A.; Mengual, J.I.; Seoane, B. Filled poly(2,6-dimethyl-1,4phenylene oxide) dense membranes by silica and silane modified silica nanoparticles: Characterization and application in pervaporation. Polymer 2005, 46, 9881-9891. [CrossRef]

44. Faykov, I.I.; Rostovtseva, V.A.; Tyan, N.S.; Pulyalina, A.Y. A Deep Eutectic Solvent as a Modifier of Polyphenylene Oxide Membranes for Acetic Acid Dehydration. Membr. Membr. Technol. 2021, 3, 124-130. [CrossRef]

45. Samanta, H.S.; Ray, S.K.; Das, P.; Singha, N.R. Separation of acid-water mixtures by pervaporation using nanoparticle filled mixed matrix copolymer membranes. J. Chem. Technol. Biotechnol. 2012, 87, 608-622. [CrossRef] 
46. Jehle, W.; Staneff, T.; Wagner, B.; Steinwandel, J. Separation of glycol and water from coolant liquids by evaporation, reverse osmosis and pervaporation. J. Memb. Sci. 1995, 102, 9-19. [CrossRef]

47. Rostovtseva, V.; Pulyalina, A.; Dubovenko, R.; Faykov, I.; Subbotina, K.; Saprykina, N.; Novikov, A.; Vinogradova, L.; Polotskaya, G. Enhancing Pervaporation Membrane Selectivity by Incorporating Star Macromolecules Modified with Ionic Liquid for Intensification of Lactic Acid Dehydration. Polymers 2021, 13, 1811. [CrossRef] [PubMed]

48. Abdelhalim, A.O.E.; Sharoyko, V.V.; Meshcheriakov, A.A.; Luttsev, M.D.; Potanin, A.A.; Iamalova, N.R.; Zakharov, E.E.; Ageev, S.V.; Petrov, A.V.; Vasina, L.V.; et al. Synthesis, characterisation and biocompatibility of graphene-L-methionine nanomaterial. J. Mol. Liq. 2020, 314, 113605. [CrossRef]

49. Abdelhalim, A.O.E.; Sharoyko, V.V.; Meshcheriakov, A.A.; Martynova, S.D.; Ageev, S.V.; Iurev, G.O.; Al Mulla, H.; Petrov, A.V.; Solovtsova, I.L.; Vasina, L.V.; et al. Reduction and functionalization of graphene oxide with L-cysteine: Synthesis, characterization and biocompatibility. Nanomed. Nanotechnol. Biol. Med. 2020, 29, 102284. [CrossRef]

50. Nagendra, B.; Cozzolino, A.; Daniel, C.; Rizzo, P.; Guerra, G.; Auriemma, F.; De Rosa, C.; D’Alterio, M.C.; Tarallo, O.; Nuzzo, A. Two Nanoporous Crystalline Forms of Poly(2,6-dimethyl-1,4-phenylene)oxide and Related Co-Crystalline Forms. Macromolecules 2019, 52, 9646-9656. [CrossRef]

51. Shukla, A.K.; Alam, J.; Alhoshan, M.S.; Ali, F.A.A.; Mishra, U.; Hamid, A.A. Thin-Film Nanocomposite Membrane Incorporated with Porous Zn-Based Metal-Organic Frameworks: Toward Enhancement of Desalination Performance and Chlorine Resistance. ACS Appl. Mater. Interfaces 2021, 13, 28818-28831. [CrossRef] [PubMed]

52. Shukla, A.K.; Alam, J.; Ansari, M.A.; Alhoshan, M.; Alam, M.; Kaushik, A. Selective ion removal and antibacterial activity of silver-doped multi-walled carbon nanotube / polyphenylsulfone nanocomposite membranes. Mater. Chem. Phys. 2019, 233, 102-112. [CrossRef]

53. Dmitrenko, M.; Liamin, V.; Kuzminova, A.; Lahderanta, E.; Solovyev, N.; Penkova, A. Modification Approaches to Enhance Dehydration Properties of Sodium Alginate-Based Pervaporation Membranes. Membranes 2021, 11, 255. [CrossRef] [PubMed]

54. Polotskaya, G.A.; Penkova, A.V.; Pientka, Z.; Toikka, A.M. Polymer membranes modified by fullerene C60 for pervaporation of organic mixtures. Desalin. Water Treat. 2010, 14, 83-88. [CrossRef]

55. Manshad, S.; Sazegar, M.R.; Mohd Nawawi, M.G.; bin Hassan, H. Fabrication of nanohybrid polyetherimide/graphene oxide membranes: Biofuel dehydration by pervaporation process. RSC Adv. 2016, 6, 103888-103894. [CrossRef]

56. Abdul Wahab, M.S.; Rahman, S.A.; Samah, R.A. Hydrophilic enhancement of Polysulfone membrane via Graphene Oxide embedded thin film nanocomposite for Isopropanol dehydration. Vacuum 2020, 180, 109569. [CrossRef]

57. Huang, A.; Feng, B. Synthesis of novel graphene oxide-polyimide hollow fiber membranes for seawater desalination. J. Memb. Sci. 2018, 548, 59-65. [CrossRef]

58. Mokhtarzadeh, S.; Agbolaghi, S.; Mansourpanah, Y. Novel Branched Polyamide/Poly(acrylonitrile)/Graphene Oxide Membranes for Separation of Chlorinated Volatile Organic Compounds from Water via Pervaporation. Macromol. Res. 2020, 28 , 797-804. [CrossRef]

59. Farivar, F.; Lay Yap, P.; Karunagaran, R.U.; Losic, D. Thermogravimetric Analysis (TGA) of Graphene Materials: Effect of Particle Size of Graphene, Graphene Oxide and Graphite on Thermal Parameters. C 2021, 7, 41. [CrossRef]

60. Favre, E.; Bounaceur, R.; Roizard, D. Biogas, membranes and carbon dioxide capture. J. Memb. Sci. 2009, 328, 11-14. [CrossRef]

61. Reid, R.C.; Prausnitz, J.M.; Polimg, B.E. The Properties of Gases E Liquids, 4th ed.; McGraw-Hill Book Company: New York, NY, USA, 1987. 